\title{
Three-dimensional numerical investigations of new Austrian tunnelling method (NATM) twin tunnel interactions
}

\author{
C.W.W. Ng, K.M. Lee, and D.K.W. Tang
}

\begin{abstract}
A series of systematic, three-dimensional coupled finite element analyses was carried out to investigate the multiple interactions between large parallel hypothetical twin tunnels constructed in stiff clay using the new Austrian tunnelling method. Special attention was paid to the influence of lagging distance between the twin tunnel excavated faces $\left(L_{\mathrm{T}}\right)$ and the load-transfer mechanism between the two tunnels. It is found that $L_{\mathrm{T}}$ has a stronger influence on the horizontal movement than on the vertical movement of each tunnel, and it significantly affects the shortening of the horizontal diameter of the tunnels. The change of pillar width appears to be an approximately linear function of $L_{\mathrm{T}}$. The location of the maximum settlement is offset from the centerline of the pillar, and the offset increases with a range of $L_{\mathrm{T}}$ values. The magnitude of the maximum settlement is independent of $L_{\mathrm{T}}$, however. As $L_{\mathrm{T}}$ increases, there is a transfer of load from the lagging (right) tunnel to the leading (left) tunnel, resulting in an increase in the bending moment in the left tunnel but a decrease in the bending moment in the right tunnel. There is a corresponding increase in the axial force at the left springline of the left tunnel and a decrease in the axial force at the right springline of the right tunnel. Due to the twin tunnel interactions, the distributions of pore-water pressures are highly nonsymmetrical at both tunnels.
\end{abstract}

Key words: NATM, tunnel, interaction, three-dimensional, numerical.

Résumé : Une série d'analyses systématiques tridimensionnelles (3D) couplées en éléments finis a été réalisée pour étudier les interactions multiples entre deux grands tunnels jumeaux parallèles hypothétiques construits dans l'argile raide au moyen de la nouvelle méthode autrichienne de creusage de tunnels. On a porté une attention spéciale à l'influence de la distance du retard $\left(L_{\mathrm{T}}\right)$ entre les faces excavées des tunnels jumeaux. On a trouvé que $L_{\mathrm{T}}$ a une plus forte influence sur le mouvement horizontal que sur le mouvement vertical de chaque tunnel et affecte appréciablement la réduction du diamètre horizontal des tunnels. Le changement de la largeur de la colonne semble être une fonction approximativement linéaire de $L_{\mathrm{T}}$. La localisation du tassement maximum est en dehors de la ligne de centre et le décentrement augmente avec la plage de variations de $L_{\mathrm{T}}$. Cependant, l'amplitude du tassement maximal est indépendante de $L_{\mathrm{T}}$. Lorsque $L_{\mathrm{T}}$ augmente, il y a un transfert de charge du tunnel en retard (à droite) vers le tunnel de tête (à gauche), ce qui résulte en une augmentation du moment fléchissant dans le tunnel de gauche, mais une diminution du moment fléchissant dans le tunnel de droite. Il y a une augmentation correspondante de la force axiale à la retombée de gauche de la voûte du tunnel de gauche, mais une diminution dans la force axiale de la retombée de droite de la voûte du tunnel de droite. À cause des interactions des tunnels jumeaux, les distributions des pressions interstitielles sont fortement asymétriques aux deux tunnels.

Mots clés : NATM, tunnel, interaction, tridimensionnel, numérique.

[Traduit par la Rédaction]

\section{Introduction}

The demand for better and more environmentally friendly travel facilities in major cities has led to a significant increase in the interest in development of underground rail or road systems worldwide. Among many tunnelling construc-

Received 11 January 2002. Accepted 22 December 2003. Published on the NRC Research Press Web site at http://cgj.nrc.ca on 30 June 2004.

C.W.W. Ng, ${ }^{1}$ K.M. Lee, and D.K.W. Tang. Department of Civil Engineering, Hong Kong University of Science and Technology, Clear Water Bay, Kowloon, Hong Kong.

${ }^{1}$ Corresponding author (e-mail: cecwwng@ust.hk). tion methods, the new Austrian tunnelling method (NATM) has often been chosen for many contract-winning metro tunnel schemes in soft ground. The NATM is a technique in which ground exposed from excavation is temporarily supported by shotcrete as the lining (Sauer and Gold 1989). The main advantage of NATM over conventional tunnelling techniques is its outstanding flexibility. Many different support techniques can be adopted to deal with various ground conditions, allowing noncircular tunnels and the enlargement of complex interchanges. The potential for cost savings by using the NATM is very high (McWilliam 1991; Murphy 1993).

In congested cities, many new tunnels have to be planned and constructed near to or parallel to existing tunnels. Despite the increasing popularity of NATM, the current tech- 
nical understanding and knowledge of applying this construction method in soft ground, particularly for parallel twin tunnels, are still not fully understood. There is an urgent need to investigate the three-dimensional (3D) effects of the construction method so as to understand the interactive behaviour between multiple tunnels during construction.

Terzaghi (1942) and Ward and Thomas (1965) reported measurements made on full-scale parallel tunnels constructed with a pillar width of 0.425 tunnel diameters in Chicago Clay and 0.6 tunnel diameters in London Clay, respectively. In both cases, the two tunnels were installed consecutively. Due to the interaction between the parallel tunnels, it was noticed that significant radial deformations occurred in the tunnel lining of $0.1 \%$ and $0.12 \%$ of the radius of the tunnels in Chicago Clay and London Clay, respectively.

Ghaboussi and Ranken (1977) comprehensively investigated the effects of the pillar width on the construction of parallel tunnels using two-dimensional (2D) finite element analyses with linearly elastic models. They found that as the pillar width between the two tunnels decreased, there was a gradual increase in the vertical stresses in the pillar and a corresponding increase in the horizontal stresses. The deviator stress was thus almost unaffected by the pillar width. Their results indicated that for a pillar width of about twice the tunnel diameter or greater, the displacements of each of the two parallel tunnels were essentially identical to those of a corresponding single tunnel construction.

Adachi et al. (1993) carried out a series of twodimensional $1 g$ model tests to investigate the behaviour of shallow twin tunnels in sandy ground. They reported that the overburden-spacing ratio $(Z / B$, where $Z$ is the depth of the tunnel measuring from ground surface to the crown of the tunnel and $B$ is the closest distance (spacing) between two parallel tunnels) was a useful parameter to evaluate the interaction between multi-tunnel constructions. If the cover was the same, the interaction became significant with a decrease in spacing between the tunnels. On the other hand, if the spacing was kept the same, the interaction between the tunnels was intensified with an increase in the overburden thickness, especially the pressure acting on the tunnel crown.

Based on previous research work by Peck (1969), Fujita (1985) and Fang et al. (1994) developed an empirical method for estimation of ground settlement associated with single shield tunnelling. Moreover, by using the finite element results published by Hoyaux and Ladanyi (1970), Fujita and Fang et al. concluded that the principle of superposition could be applied to estimate ground surface settlements for parallel twin tunnels if the ratio of the distance between tunnel centers to the diameter of the tunnels was larger than 2.7, irrespective of the ratio of the depth to the diameter of the tunnels.

Chapman et al. (2002) carried out a series of 2D finite element analyses to study the settlement above closely spaced multiple tunnel construction in London Clay. It was found that the computed settlement trough above a second side-byside tunnel in close proximity to the first tunnel was not well predicted by the conventional simple empirical techniques based on the Gaussian distribution equation. The predicted maximum settlement above the second tunnel was offset towards the first tunnel, and the side of the trough closest to the first tunnel exhibited greater relative movements than those on the side of the trough farthest from the first tunnel. It was also found that the predicted maximum relative increase in settlement occurred above the centerline of the first tunnel driven in twin side-by-side construction and was independent of tunnel spacing.

Addenbrooke and Potts (1996) carried out a series of finite element analyses to investigate twin circular tunnel constructions. Two-dimensional coupled-consolidation analyses were adopted and the nonlinear elastic behaviour of London Clay was taken into account. With side-by-side tunnels, Addenbrooke and Potts found that the shape of the settlement trough above the second tunnel was similar to that of a greenfield site. The position of the maximum settlement trough was offset with respect to the tunnel centerline, however, towards the first (existing) tunnel. It was evident that the assumption of the superposition of settlement troughs could not account for the offset. With a pillar width less than one diameter, the eccentricity of the maximum settlement trough approached a value equal to double the pillar width, and the eccentricity decreased with an increase in the pillar width, down to less than $25 \%$ of the pillar width for a pillar width greater than several tunnel diameters. In addition, Addenbrooke and Potts also reported that the existing tunnel lining was forced to change shape during the driving of the second tunnel, resulting in an increase in the length of the horizontal diameter and a reduction in the vertical diameter.

Addenbrooke et al. (1997) further presented the significance of modelling the nonlinear elasticity and the effect of introducing a soft independent shear modulus on the prediction of 2D surface settlements. It was found that the introduction of a softer anisotropic shear modulus could significantly improve the prediction of settlements for a greenfield site but not for twin-tunnel interactions. All the models adopted by Addenbrooke et al. gave predictions of shallower and wider surface settlement profiles than the measured ones. The asymmetry of the measured profile was reproduced, but it was overexaggerated for the first tunnel.

Kim et al. (1998) performed a series of $1 \mathrm{~g}$ model tests on closely spaced tunnels in kaolin clay samples with an overconsolidation ratio (OCR) up to 3 in the short term. Three tunnels were constructed in which the two new tunnels were either parallel to the existing tunnel or perpendicular to it. From their results it was concluded that the interaction effects between the parallel tunnels were linked to the redistribution of stresses within the soil caused by liner deformation and ground loss, and the interaction mechanisms were extremely complex.

Although a considerable amount of research work on multi-tunnel interactions has been carried out, simplified 2D numerical analyses and $1 g$ model tests have often been adopted to investigate the complex 3D multi-tunnel interactions. Very little research has been reported in which twin parallel tunnels, particularly noncircular NATM tunnels, have been investigated using $3 \mathrm{D}$ numerical techniques, even after Dasari et al. (1996) and Tang et al. (1999) reported a number of 3D numerical analyses of a single NATM tunnel. Because of an increasing popularity of the NATM and an increasing number of closely spaced underground tunnels planned and constructed in cities worldwide, there is a definite need to improve our understanding of multi- non- 
circular NATM tunnel interactions. In this paper, a series of $3 \mathrm{D}$ numerical simulations are carried out to investigate the interactions between two parallel hypothetical noncircular tunnels constructed using the NATM. The geometry of the tunnel, the construction method, and the ground conditions adopted in the 3D simulations are similar to those for the Heathrow trial tunnel (New and Bowers 1994; Deane and Bassett 1995).

\section{Heathrow trial tunnel}

The $100 \mathrm{~m}$ long Heathrow trial tunnel was the first tunnel excavated by the NATM in stiff London Clay. The tunnel is located on a section of the proposed tunnel alignment running from the Central Terminal Area to Terminal 4 of Heathrow Airport, London, U.K. The tunnel has an oval cross section, a height of about $8 \mathrm{~m}$, a section width of about $9 \mathrm{~m}$, a face area of about $59 \mathrm{~m}^{2}$, and a depth below ground of approximately $20 \mathrm{~m}$. At the trial tunnel, three different kinds of construction sequences were evaluated to examine the method performance and suitability. The $100 \mathrm{~m}$ long tunnel construction was divided into three different excavation sequences (or types), each over a length of about $35 \mathrm{~m}$. The three trial designs were based on excavation sequences successfully used elsewhere in Europe. The first (type 1) construction sequence was the most conservative and consisted of two side headings followed by the removal of the central core of the tunnel. The second sequence (type 2) used excavation on one side of the tunnel and then enlargement of the original excavation to its full size. The third type (type 3 ) was a top heading and bench sequence with the bottom of the shotcrete arch of the heading supported on inverted shotcrete arches. A typical section of the type 2 construction sequence is shown in Fig. 1. Details of the construction sequences have been reported by New and Bowers (1994) and Deane and Bassett (1995).

The type 2 construction was distinctively asymmetric, with the left drift of $29.8 \mathrm{~m}^{2}$ completed prior to the right drift of $28.8 \mathrm{~m}^{2}$. The lining consisted of a $250 \mathrm{~mm}$ shotcrete shell with a single layer of steel mesh, and lattice girders were used at $1 \mathrm{~m}$ centers along the tunnel. Twelve days were taken for excavation of the left drift and another 12 days for the remaining part of the tunnel. The maximum ground surface settlement measured for the left drift and on the completion of the whole tunnel excavation was 14.5 and $26.8 \mathrm{~mm}$, respectively, whereas the volume loss was determined to be $1.24 \%$ and $1.05 \%$, respectively. The standard deviation, $i$, which provides a means of defining the trough width, was $9 \mathrm{~m}$ on the completion of the entire tunnel excavation. Since the type 2 construction sequence gave the best performance in terms of surface settlement and volume loss among the three types of excavations, it has therefore been adopted for the hypothetical 3D numerical simulations of twin tunnel interactions in this paper.

\section{Three-dimensional modelling of NATM twin tunnel construction}

Tunnel geometry, finite element mesh, and initial ground conditions

Figures $2 a, 2 b$, and $2 c$ show a $3 \mathrm{D}$ isometric view, a typi-
Fig. 1. Cross section of the trial tunnel (after Deane and Bassett 1995).

\begin{tabular}{lc}
\hline Taplow Gravel & $5 \mathrm{~m}$ \\
\hline London Clay & $\uparrow$
\end{tabular}

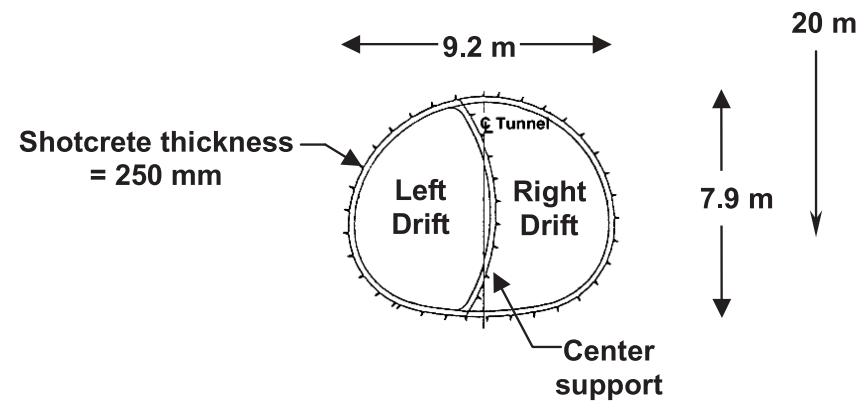

cal section, and a plan view of the finite element mesh of the twin parallel tunnels, respectively. The finite element program ABAQUS (Abaqus, Inc. 1998) was adopted. The modelled tunnel is oval in shape and $9.2 \mathrm{~m}$ and $7.9 \mathrm{~m}$ in horizontal and vertical diameter, respectively, i.e., similar to that at the Heathrow trial as shown in Fig. 1 (Deane and Bassett 1995). The length of the mesh in the lateral $(x)$ direction is $178 \mathrm{~m}$ (approximately $10.3 \mathrm{D}$ from the centerline to both sides, where $D$ is the equivalent diameter of a tunnel equal to $8.64 \mathrm{~m}$ ). The length in the longitudinal direction and the depth of the mesh were $142.5 \mathrm{~m}(16.5 \mathrm{D})$ and $45 \mathrm{~m}$ (5.2D), respectively. The centerline of each tunnel is located at a depth of $20 \mathrm{~m}(2.3 D)$, and the pillar width between the two tunnels is $1.0 D$.

Figure 3 shows the cross section of the finite element mesh for the twin tunnels consists of 17220 threedimensional, eight-node cubic isoparametric solid elements for the soils. At each node of the solid elements, there are three degrees of freedom describing displacements in the $x$, $y$, and $z$ directions. For the shotcrete lining, 4516 four-node shell elements are used. At each node, there are six degrees of freedom: three for displacements and three for rotations. All the elements used in all the analyses are first-order elements. The total number of nodes is 14868 .

The movements in all directions and rotations are fixed at the bottom of the mesh. Roller boundaries are used for the vertical faces of the mesh. In addition, no horizontal displacements are permitted on the two $x-z$ planes (i.e., $y=0$ and $y=142.5$ ) at the boundaries of the mesh (see Fig. 2).

Free drainage was modelled at the vertical boundaries of the mesh, and a hydrostatic pore-water pressure of $400 \mathrm{kPa}$ was fixed at the bottom of the mesh. Free drainage was allowed at the excavated tunnel face. On the other hand, the shotcrete lining was modelled as an impermeable material, and hence water flow through the lining was not permitted.

The modelled ground conditions consisted of $5 \mathrm{~m}$ of Taplow Gravel overlying the $40 \mathrm{~m}$ thick London Clay with coefficient of earth pressure at rest $K_{0}=1.5$. The initial hydrostatic groundwater table was assumed to be located at the interface between the two soil strata. Effective coupled con- 
Fig. 2. Three-dimensional isometric view of the finite element mesh of the twin parallel tunnels: $(a)$ 3D isometric view; $(b)$ typical section (side view from positive $x$ direction); $(c)$ plan view.
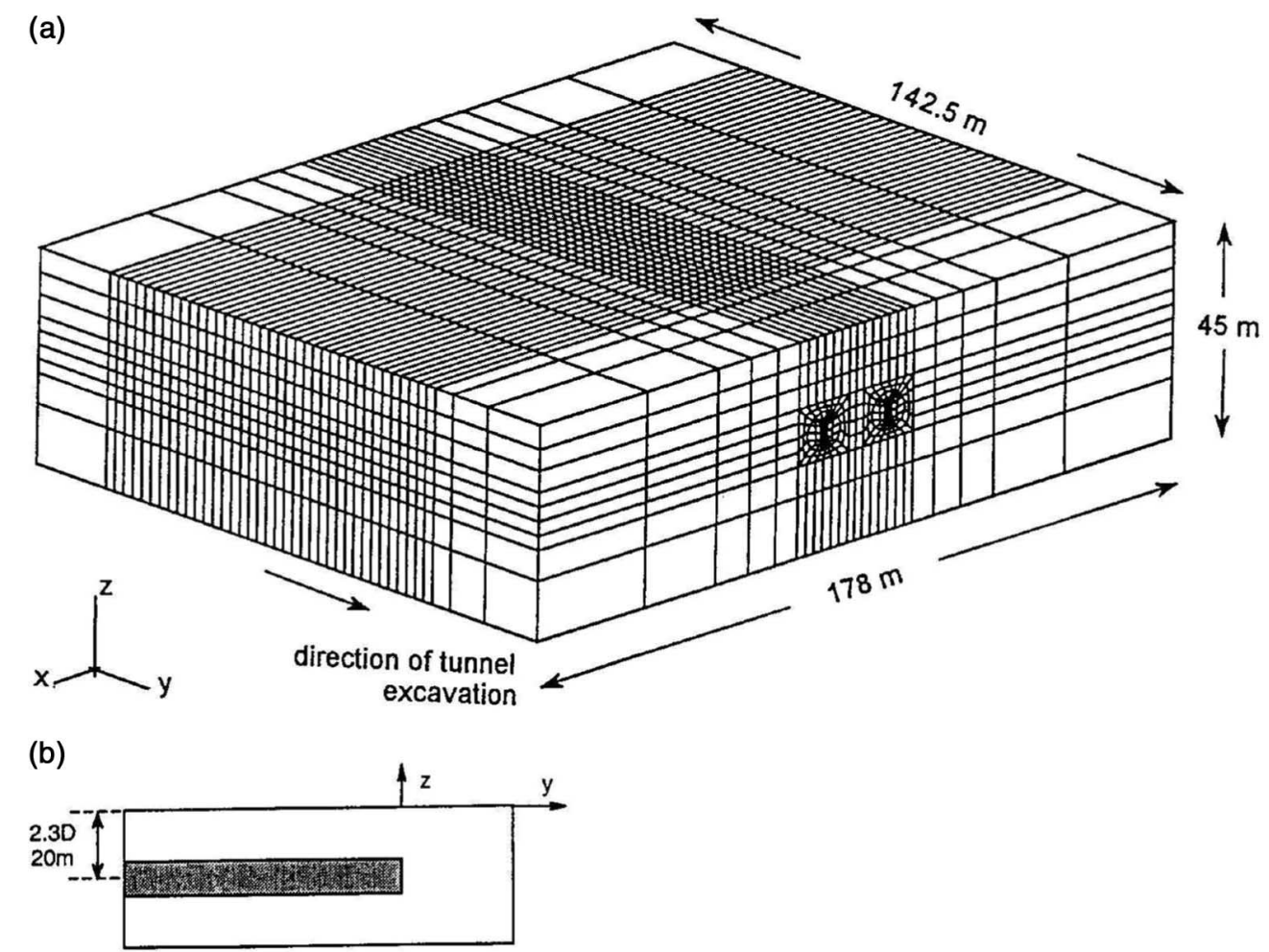

(c)

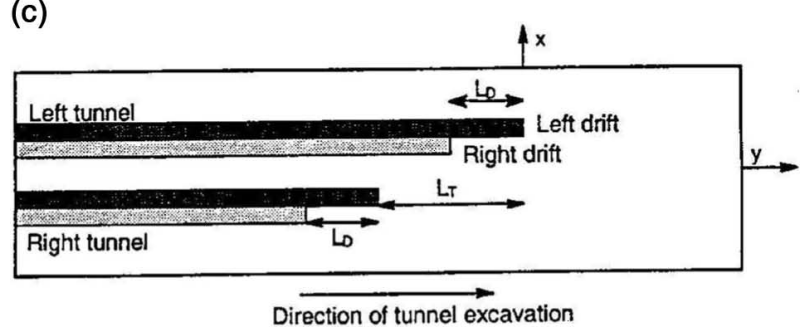

solidation analyses were carried out to simulate the excavation rate of $2.5 \mathrm{~m}$ per day for either the left or right drift.

\section{Finite element simulation procedures}

The sequence of the tunnel excavation was idealized and modelled (refer to Fig. 2 for an illustration of the parallel tunnels) as follows: (i) excavate the left drift of the left tunnel; (ii) install the shotcrete lining on the exposed surface (i.e., left drift of the left tunnel), leaving a constant unsupported span length $L_{\mathrm{U}}=5 \mathrm{~m}$ behind the tunnel face; (iii) excavate the right drift of the left tunnel at a lagged distance $L_{\mathrm{D}}=2.3 D$ (i.e., $20 \mathrm{~m}$ ) behind the tunnel face of the left drift; (iv) install the shotcrete lining on the exposed surface (i.e., right drift of the left tunnel), leaving the same unsupported $L_{\mathrm{U}}$ of $5 \mathrm{~m} ;(v)$ excavate the left drift of the right tunnel at a distance of $L_{\mathrm{T}}$ behind the tunnel face of the left drift of the first tunnel; ( $v i$ ) install the shotcrete lining on the exposed surface (left drift of the right tunnel) of the second tunnel, leaving the same unsupported $L_{\mathrm{U}}$ of $5 \mathrm{~m}$; (vii) excavate the right drift of the right tunnel at $L=2.3 D$ behind the tunnel face of the left drift of the right tunnel; (viii) install the shotcrete lining on the exposed surface (right drift of the right tunnel) of the second tunnel, leaving the same $L_{\mathrm{U}}$ of $5 \mathrm{~m}$; (ix) repeat steps (i) to (viii) until the two tunnels are completed.

In this paper, five different lagged distances (i.e., $L_{\mathrm{T}}=$ $0 D, 0.6 D, 1.2 D, 2.3 D$, and $3.5 D$ ) between the left tunnel (first tunnel) and the right tunnel (second tunnel) were studied and analysed. A study of different lagged distances (i.e., $L_{\mathrm{D}}$ ) within a single tunnel is presented by Tang et al. (1999) and Tang (2001), and some results are adopted in this paper for comparison.

\section{Constitutive models and parameters}

The Taplow Gravel and London Clay were modelled as isotropic and anisotropic elastic - perfectly plastic materials with a modified Drucker-Prager yield criterion (Abaqus, Inc. 1998), respectively. The Drucker-Prager failure criterion, $F$, and the flow potential, $G$, are defined as follows:

$$
F=t-p^{\prime} \tan \beta-d^{\prime}=0
$$

$$
G=t-p^{\prime} \tan \varphi
$$


Table 1. Material parameters adopted in the finite element analyses.

\begin{tabular}{llll}
\hline & Taplow Gravel & London Clay & Shotcrete \\
\hline Saturated density $\left(\mathrm{kN} / \mathrm{m}^{3}\right)$ & 20 & 20 & 24 \\
Void ratio & 0.4 & 1.0 & na \\
Coefficient of permeability $(\mathrm{m} / \mathrm{s})$ & $1 \times 10^{-4}$ & $1 \times 10^{-9}$ & na \\
$K_{0}$ & 0.43 & 1.5 & na \\
$E_{\mathrm{v}}{ }^{\prime}$ or Young's modulus, $E^{\prime}(\mathrm{kPa})$ & $7.5 \times 10^{4}$ & $7500+3900 z^{a}$ & $3.0 \times 10^{7}$ \\
$E_{\mathrm{h}}{ }^{\prime}$ & na & $1.6 E_{\mathrm{v}}^{\prime}$ & na \\
Poisson's ratio, $\mu_{\mathrm{vh}}{ }^{\prime}$ or $\mu^{\prime}$ & 0.2 & 0.125 & 0.3 \\
Poisson's ratio, $\mu_{\mathrm{hh}}{ }^{\prime}$ & na & 0.125 & na \\
Shear modulus, $G_{\mathrm{vh}}$ & na & $0.44 E_{\mathrm{v}}{ }^{\prime}$ & na \\
Frictional parameter, $\beta^{\prime}\left({ }^{\circ}\right)$ & $54.8\left(\phi^{\prime}=30^{\circ}\right)$ & $40.6\left(\phi^{\prime}=22^{\circ}\right)$ & na \\
Cohesion parameter, $d^{\prime}(\mathrm{kPa})$ & $0.0\left(c^{\prime}=0 \mathrm{kPa}\right)$ & $14.8\left(c^{\prime}=5 \mathrm{kPa}\right)$ & na \\
Angle of dilation, $v^{\prime}\left({ }^{\circ}\right)$ & 17.5 & 11.0 & na \\
\hline
\end{tabular}

Note: na, not available.

${ }^{a} z$, depth below the ground surface (in metres).

Fig. 3. Cross sections of the finite element mesh of the twin parallel tunnels: (a) $x-z$ plane; (b) $x-y$ plane.

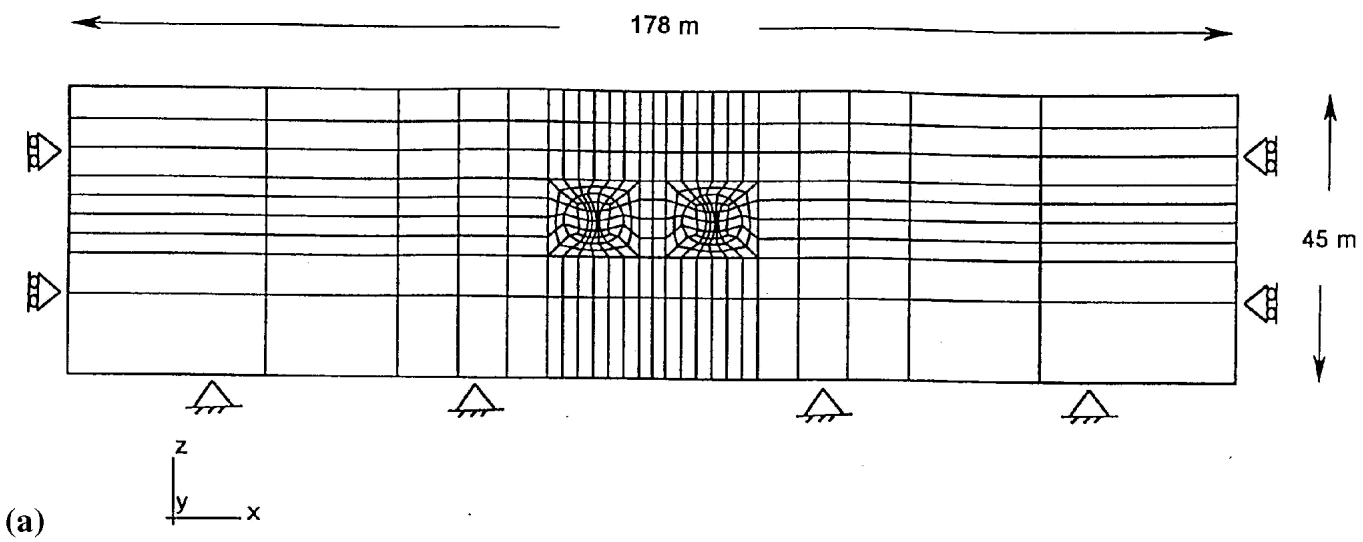

(a)

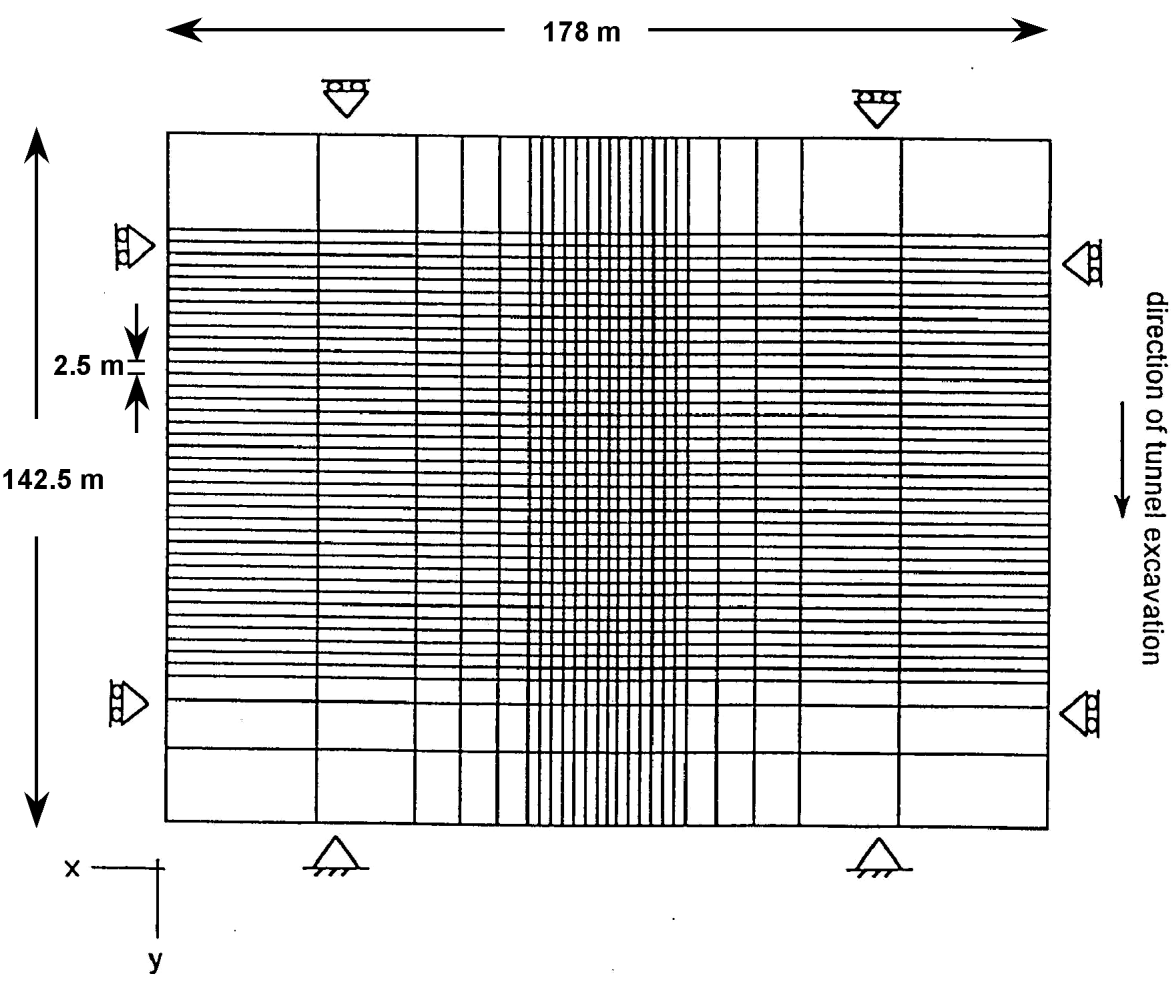


Fig. 4. Deformation at the tunnel periphery at different sections for $L_{\mathrm{T}}=0 D:(a)$ at $y=0 \mathrm{~m}$ or $0 D($ section $\mathrm{A}-\mathrm{A}) ;(b)$ at $y=$ $-20 \mathrm{~m}$ or $-2.3 D$ (section $\mathrm{B}-\mathrm{B}$ ); $(c)$ at $y=-75 \mathrm{~m}$ or $-8.6 D$ (section E-E, approaching the plane strain conditions). LLD, left drift of the left tunnel; LRD, right drift of the left tunnel; RLD, left drift of the right tunnel; RRD, right drift of the right tunnel.

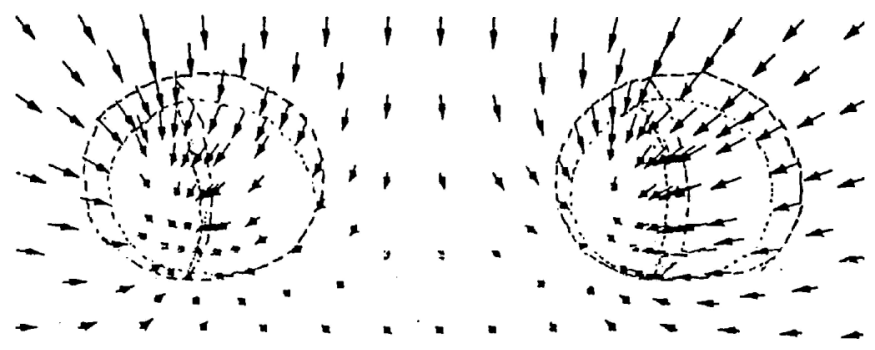

(a)

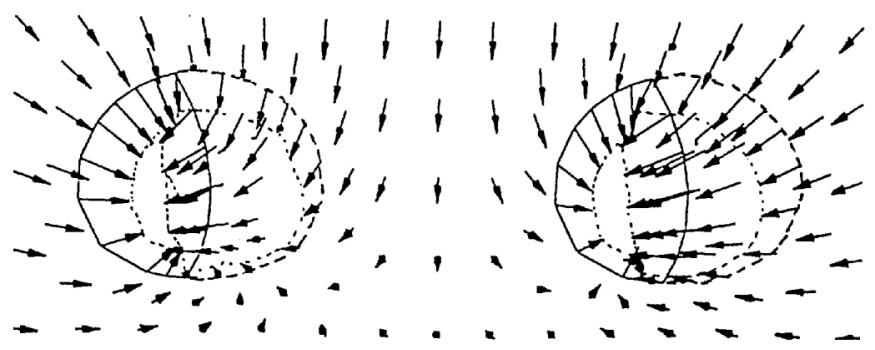

(b)

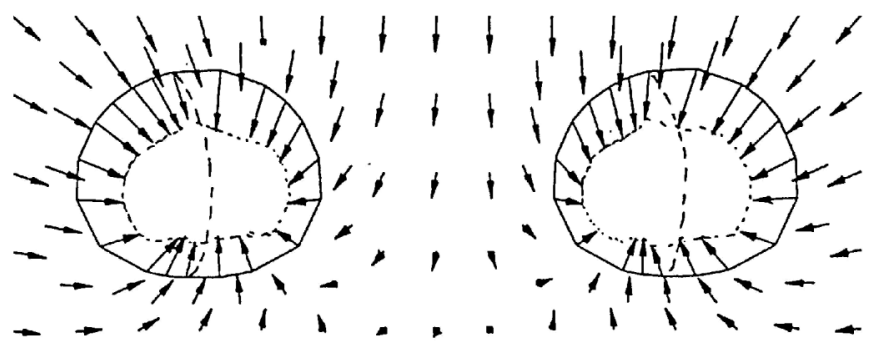

(c)

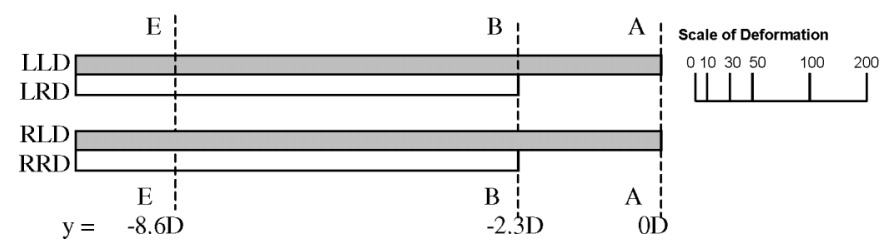

where $t$ is the deviator stress, $p^{\prime}$ is the mean effective stress, $\beta$ is the friction angle, $d^{\prime}$ is the effective cohesion, and $\varphi$ is the dilation angle in the $p^{\prime}-t$ plane. Details of the definition of each term are given by Abaqus, Inc. (1998), and a summary of the model parameters used is given in Table 1. It should be noted that the strength parameters using the Mohr-Coulomb failure criterion are also given in Table 1 for ease of comparison. To convert the Mohr-Coulomb parameters for the Drucker-Prager model, the same failure criterion in triaxial compression is used for both models. This approach implies London Clay and Taplow Gravel pos- sess an internal angle of friction of $22^{\circ}$ and $30^{\circ}$, respectively. In modelling elastic cross-anistropy of London Clay, the orthotropic effective stiffness parameters adopted for the finite element analyses of the new Queen Elizabeth II Conference Centre excavation in London Clay (Burland and Kalra 1986) are used. The five parameters required for an anisotropic analysis are as follows: $(i)$ effective Young's modulus $(\mathrm{kPa})$ in the vertical direction, $E_{\mathrm{v}}^{\prime}=7500+3900 z$, where $z$ is the depth below the ground surface; (ii) effective Young's modulus in the horizontal direction, $E_{\mathrm{h}}^{\prime}=1.6 E_{\mathrm{v}}^{\prime}$; (iii) Poisson's ratio for the effect of the vertical strain on the horizontal strain, $\mu_{\mathrm{vh}}^{\prime}=0.125$; (iv) Poisson's ratio for the effect of the horizontal strain on the complementary horizontal strain, $\mu_{\mathrm{hh}}^{\prime}=0.125$; and $(v)$ shear modulus in the verticalhorizontal plane, $G_{\mathrm{vh}}=0.444 E_{\mathrm{v}}^{\prime}$.

It is not always easy to correctly assess the mass permeability for London Clay because of the presence of fissures and sand lenses in some places. A range of values varying from $10^{-8}$ to $10^{-11} \mathrm{~m} / \mathrm{s}$ has been reported in the literature (Mair and Taylor 1997; Addenbrooke and Potts 2001; Withers et al. 2001). In light of the reported range and considering the effects of stress relief due to excavation, the water permeability of $10^{-9} \mathrm{~m} / \mathrm{s}$ was assumed for London Clay in the analyses.

The shotcrete lining was modelled as an impermeable isotropic linear elastic material with a Young's modulus of $30 \times$ $10^{6} \mathrm{kN} / \mathrm{m}^{2}$ and a Poisson's ratio of 0.3 (Oettl et al. 1998). A summary of the model parameters used in the analyses is given in Table 1.

\section{Computed results}

\section{Ground deformations around twin tunnels}

Figures $4 a-4 c$ show the displacement vectors at three different sections around the two parallel tunnels for $L_{\mathrm{T}}=0 D$ (i.e., no lagged distance between the faces of the tunnels, $L_{\mathrm{T}}=0$; refer to Fig. 2 for the definition of $L_{\mathrm{T}}$ ). At the tunnel excavation face (i.e., section $\mathrm{A}-\mathrm{A}$ at $y=0$ ), the displacement vectors are approximately symmetrical about the centerline of the pillar between the two tunnels (see Fig. 4a). Clearly, the soil moves toward the left drift of each tunnel as a result of the stress reduction due to the excavation, except for the soil located in the region of the pillar, where the soil essentially deforms vertically downward with little horizontal displacement because of the interaction between the two tunnels. The interaction also leads to about 50\% larger lateral deformation (i.e., $28.5 \mathrm{~mm}$ or $0.33 \% \mathrm{D}$ ) at the left springline of the left tunnel than that (i.e., $15.5 \mathrm{~mm}$ or $0.18 \% \mathrm{D}$ ) of the right tunnel. On the contrary, the lateral deformation at the right springline of the right tunnel is more than twice that at the right springline of the left tunnel. This indicates that the twin tunnel interaction leads to a reduction in the lateral movements between them.

As shown in Figs. $4 b$ and $4 c$, similar deformation patterns are observed at both section B-B (i.e., at $20 \mathrm{~m}, y=-20 \mathrm{~m}$, behind the exposed face of the left drift of each tunnel) and section E-E (i.e., at $75 \mathrm{~m}, y=-75 \mathrm{~m}$ or $-8.6 D$, behind the exposed face of the left drift of each tunnel, which is approaching the plane strain conditions). It should be noted that there is an increase of $43.6 \mathrm{~mm}$ in the width of the pillar as a result of inward movements of 20.7 and $22.9 \mathrm{~mm}$ at the 
Fig. 5. Deformation at the tunnel periphery at different sections for $L_{\mathrm{T}}=3.5 D$ : $(a)$ at $y=0 \mathrm{~m}$ or $0 D(\operatorname{section} \mathrm{A}-\mathrm{A})$; $(b)$ at $y=-20 \mathrm{~m}$ or $-2.3 D$ (section $\mathrm{B}-\mathrm{B}) ;(c)$ at $y=-30 \mathrm{~m}$ or $-3.5 D$ (section $\mathrm{C}-\mathrm{C}) ;(d)$ at $y=-50 \mathrm{~m}$ or $-5.8 D(\operatorname{section} \mathrm{D}-\mathrm{D}) ;(e)$ at $y=-75 \mathrm{~m}$ or $-8.6 D$ (section E-E, approaching the plane strain conditions). Abbreviations as in Fig. 4.

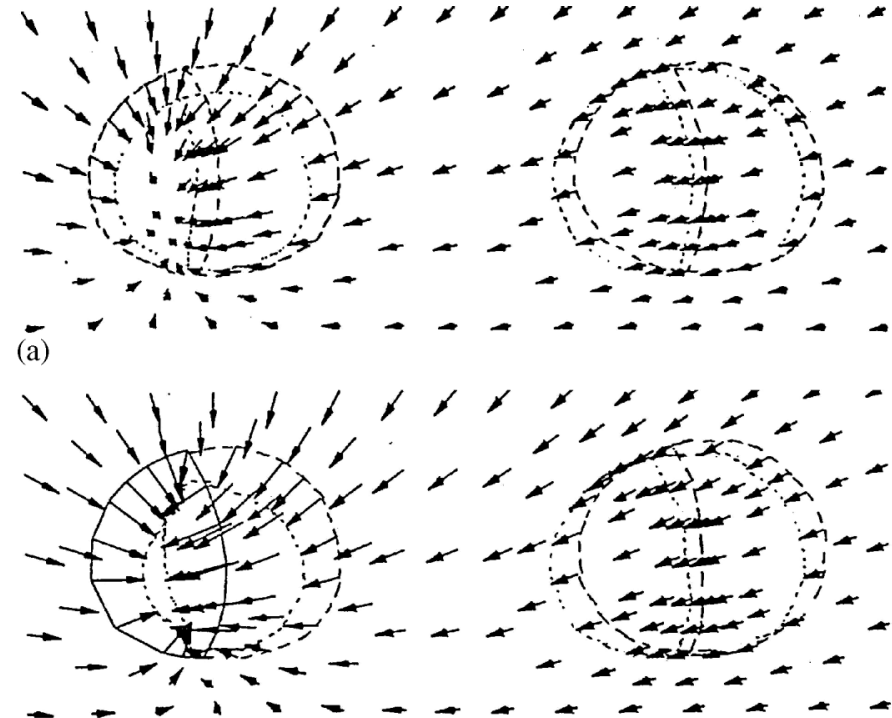

(b)

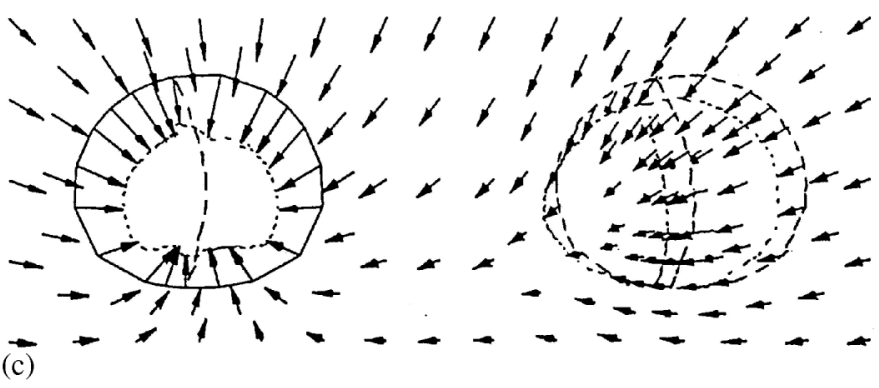

springline of the left and right tunnels, respectively. Compared with a corresponding $31.7 \mathrm{~mm}$ inward movement at the springline of a similar single NATM tunnel constructed in a greenfield site (Tang 2001), the twin tunnel construction and interaction result in $28 \%-35 \%$ reduction in the lateral movement of each tunnel.

Figures $5 a-5 e$ show the displacement vectors at five different sections around the two parallel tunnels for $L_{\mathrm{T}}=30 \mathrm{~m}$ or $3.5 D$ (i.e., the construction of the right tunnel lags behind that of the left tunnel by $30 \mathrm{~m}$ ). At section A-A (see Fig. $5 a$ ), i.e., $y=0 D$, all the soil moves toward the excavated left drift of the left tunnel. The soil deformations at the right tunnel are dominated by the horizontal component of the displacement vectors, suggesting that the effects of the horizontal stress reduction on the ground movements are more significant (due to the high $K_{0}$ ) than the effects of vertical stress reduction, as opposed to the case shown in Fig. $5 a$. As the distance behind the excavated left drift of the left tunnel increases from 0 to $30 \mathrm{~m}(3.5 \mathrm{D})$, the vertical component of the displacement vectors gradually becomes more significant as a result of the construction of the right tunnel (see Figs. $5 b, 5 c$, and $5 d$ ). At section E-E (approaching the plane strain conditions), the deformation patterns are almost symmetric about the centerline of the pillar (see Fig. 5e). Both the horizontal and vertical diameters of the opening of each tunnel are shortened due to the stress reduction and tunnel interaction.

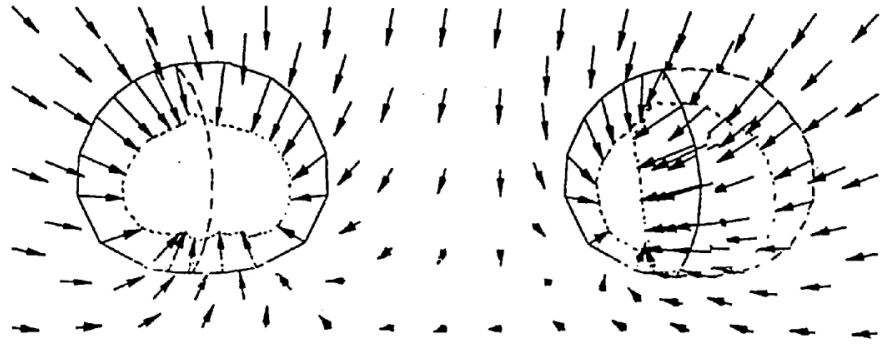

(d)

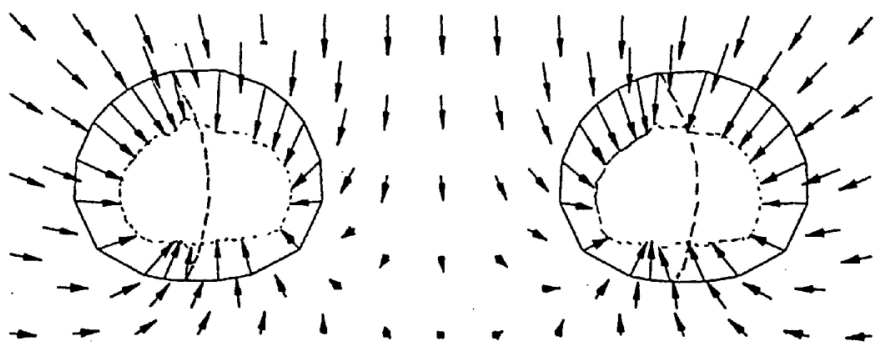

(e)

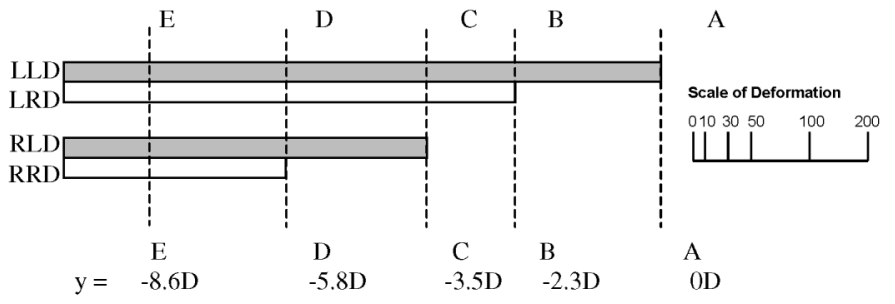

\section{Deformations and movements of twin tunnels}

Figures $6 a$ and $6 b$ show the deformation at the tunnel periphery at section $\mathrm{E}-\mathrm{E}$ for $L_{\mathrm{T}}=0$ and $30 \mathrm{~m}$, respectively. It appears that $L_{\mathrm{T}}$ has a greater influence on the horizontal deformation at the springline than on the vertical movement at the crown of each tunnel. The lateral deformation of the left tunnel away from the pillar increases from $20.7 \mathrm{~mm}$ for $L_{\mathrm{T}}=$ $0 \mathrm{~m}$ to $23.1 \mathrm{~mm}$ for $L_{\mathrm{T}}=30 \mathrm{~m}$ (11.5\% increase), whereas the lateral deformation of the right springline of the right tunnel decreases from $22.9 \mathrm{~mm}$ to $18.7 \mathrm{~mm}$ as $L_{\mathrm{T}}$ increases (i.e., $18.6 \%$ decrease from $L_{\mathrm{T}}=0$ to $30 \mathrm{~m}$ ). On the contrary, the vertical movements at the crown appear to be less sensitive to the $L_{\mathrm{T}}$ value. In their $1 g$ laboratory model tests in normally consolidated clay and overconsolidated clays of OCR up to 3, Kim et al. (1998) reported that the incremental displacements were concentrated at the pillar springline and the crown of the existing tunnel. After the installation of the right (new) tunnel, the pillar springline moved towards the right tunnel and the crown moved downwards. They also reported that the centerline of the existing tunnel moved slightly towards the new tunnel. All these test results are consistent with the $3 \mathrm{D}$ numerical analyses described in this study.

As shown in Fig. 6, there is a decrease in diameter at the tunnel periphery in the two tunnels, but the magnitudes are different in the vertical and horizontal diameters. The shortening in the vertical diameter of the left tunnel is $75.8 \mathrm{~mm}$ 
Fig. 6. Comparison of the deformations at section E-E $(y=-8.6 D$, approaching the plane-strain conditions $)$ for $(a) L_{\mathrm{T}}=0 D$, and (b) $L_{\mathrm{T}}=3.5 D(30 \mathrm{~m})$.
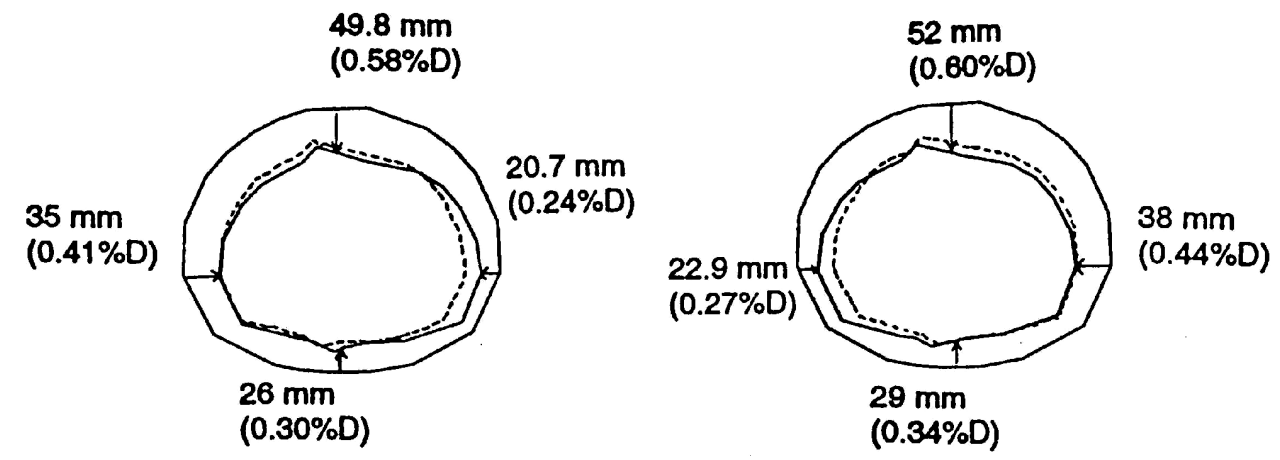

Decrease in diameters at the tunnel periphery

(i) vertical diameter

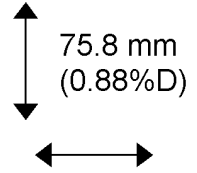

(ii) horizontal diameter

(a)

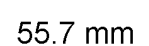

(0.64\%D)

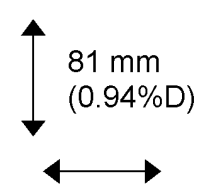

$60.9 \mathrm{~mm}$

$(0.70 \% \mathrm{D})$
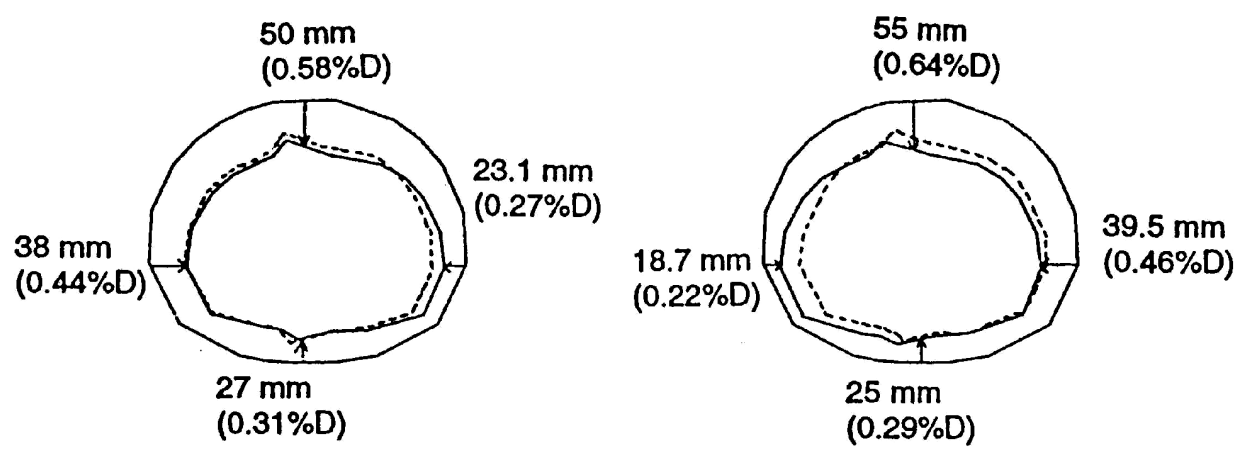

Decrease in diameters at the tunnel periphery

(i) vertical diameter

(ii) horizontal diameter

(b)

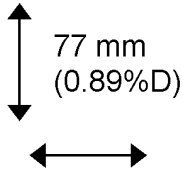

$61.1 \mathrm{~mm}$

$(0.71 \% \mathrm{D})$

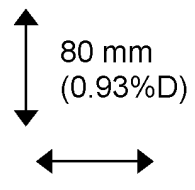

$58.2 \mathrm{~mm}$

$(0.67 \% \mathrm{D})$ (or $0.88 \% \mathrm{D}$ ) and $77 \mathrm{~mm}$ (or $0.89 \% \mathrm{D}$ ), whereas for the right tunnel it is $81 \mathrm{~mm}$ (or $0.94 \% \mathrm{D}$ ) and $80 \mathrm{~mm}$ (or $0.93 \% \mathrm{D}$ ) for $L_{\mathrm{T}}=0$ and $30 \mathrm{~m}$, respectively. The shortening in the vertical tunnel diameter appears to be independent of $L_{\mathrm{T}}$. On the contrary, $L_{\mathrm{T}}$ has a stronger influence on the shortening in the horizontal diameter of both tunnels. For the left tunnel, the shortening of the horizontal diameter increases from $55.7 \mathrm{~mm}($ or $0.64 \% \mathrm{D})$ for $L_{\mathrm{T}}=0 \mathrm{~m}$ to $61.1 \mathrm{~mm}($ or $0.71 \% \mathrm{D}$ ) for $L_{\mathrm{T}}=30 \mathrm{~m}$. This suggests that a portion of the load is taken up by the left tunnel as $L_{\mathrm{T}}$ increases, resulting in an increased reduction in the diameter of the tunnel periphery.
This is consistent with a decrease in the shortening of the right tunnel diameter from $60.9 \mathrm{~mm}$ (or $0.70 \% \mathrm{D}$ ) to $58.2 \mathrm{~mm}$ (or $0.67 \% \mathrm{D}$ ) for $L_{\mathrm{T}}=0$ and $30 \mathrm{~m}$, respectively, since less of the load is shared by the right tunnel as $L_{\mathrm{T}}$ increases. The postulated load transfer from the right tunnel to the left tunnel as $L_{\mathrm{T}}$ increases is further illustrated and verified by considering the induced bending moment and the axial force distributions.

\section{Surface settlements}

Figure 7 shows the surface settlement profiles above the 
Fig. 7. Normalized longitudinal surface ground settlements at different sections for $L_{\mathrm{T}}=3.5 D$. FE, finite element. Other abbreviations as in Fig. 4.

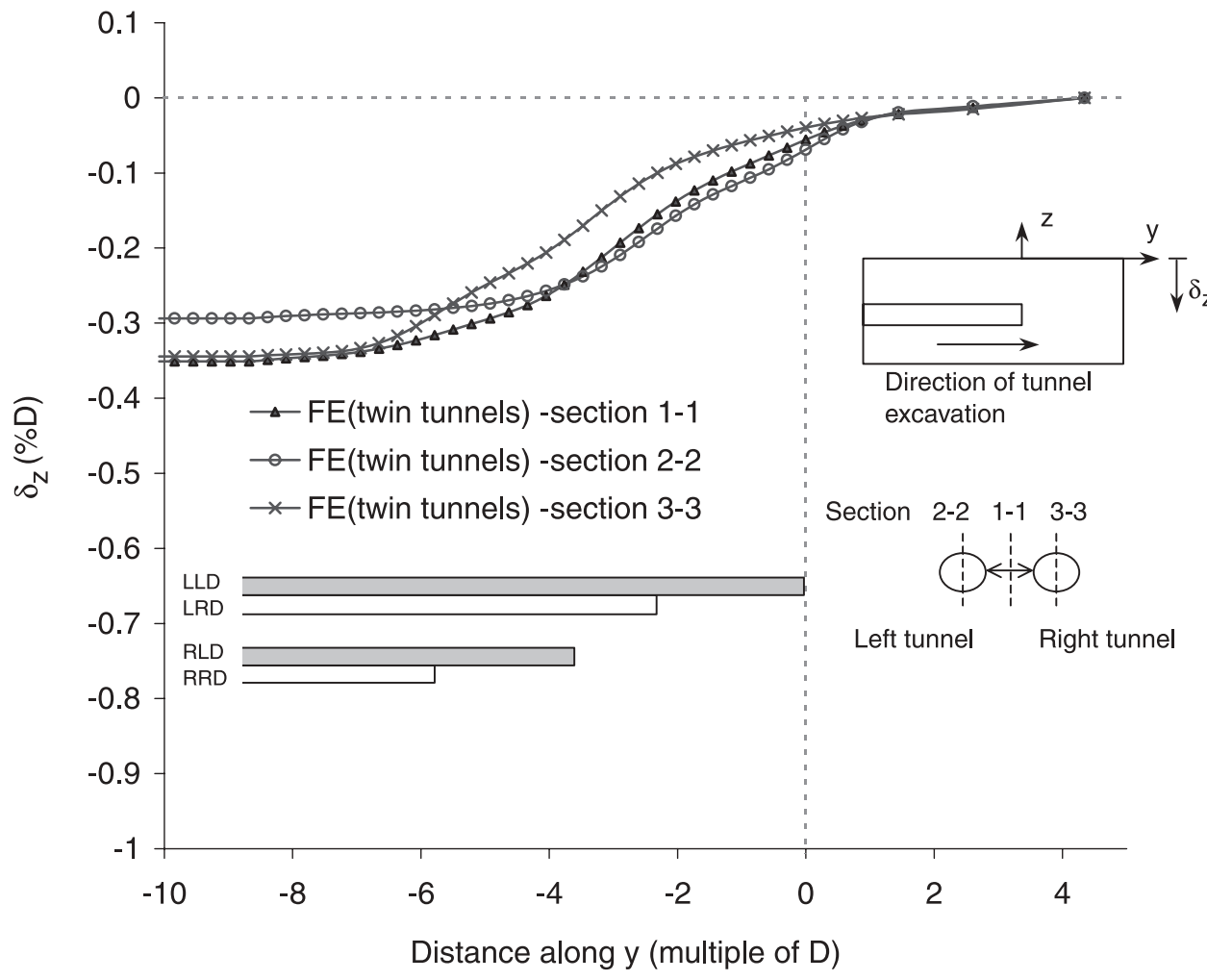

Fig. 8. Normalized surface ground settlements at various longitudinal distances for $L_{\mathrm{T}}=3.5 D$.

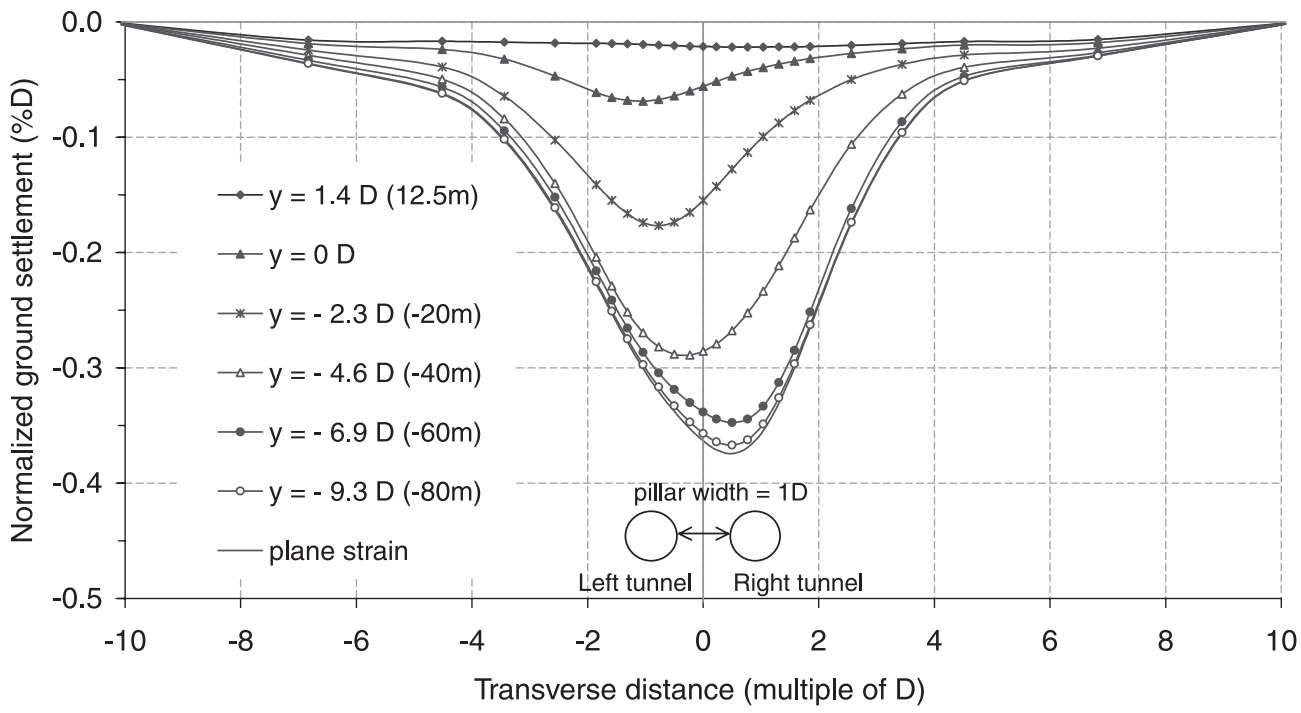

centerline of each tunnel and the pillar along the longitudinal axes of the tunnels (i.e., the $y$ direction) for $L_{\mathrm{T}}=3.5 \mathrm{D}$. For ease of comparisons, the computed settlements and the longitudinal distances are normalized by the equivalent diameter of the tunnel. It can be seen that the settlement above the left tunnel (section 2-2) is largest close to its excavated face among the three sections and approaches a constant value of $-0.29 \% D$ at a distance of $4 D$ behind the excavated face of the left drift of the left tunnel. The settlement profile above the centerline of the pillar (i.e., section 1-1) is very similar to that at section $2-2$, but the former gradually ex- ceeds the latter at $y=-3.5 D$ or $-30 \mathrm{~m}$ with the approach of the right drift of the right tunnel.

The settlement above the right tunnel (i.e., section 3-3) is smallest prior to the construction of the right drift of the right tunnel, but it exceeds the settlement above the left tunnel at $y=-5.8 D$ or $-50 \mathrm{~m}$ and gradually resembles that above the centerline of the pillar. This reveals that the settlement trough shifts from the left to the right of the centerline of the pillar as the tunnel construction advances. This phenomenon is consistent with the patterns of the displacement vectors shown in Fig. 4. At the location where the right tun- 
Fig. 9. Relationship between net offsets of ground surface settlement troughs $\left(\Delta L_{x}=L_{x}\right.$ minus $L_{x}$ from twin tunnel analysis with $\left.L_{\mathrm{T}}=0\right)$ at section E-E $(y=-8.6 D$, approaching the plane strain conditions).

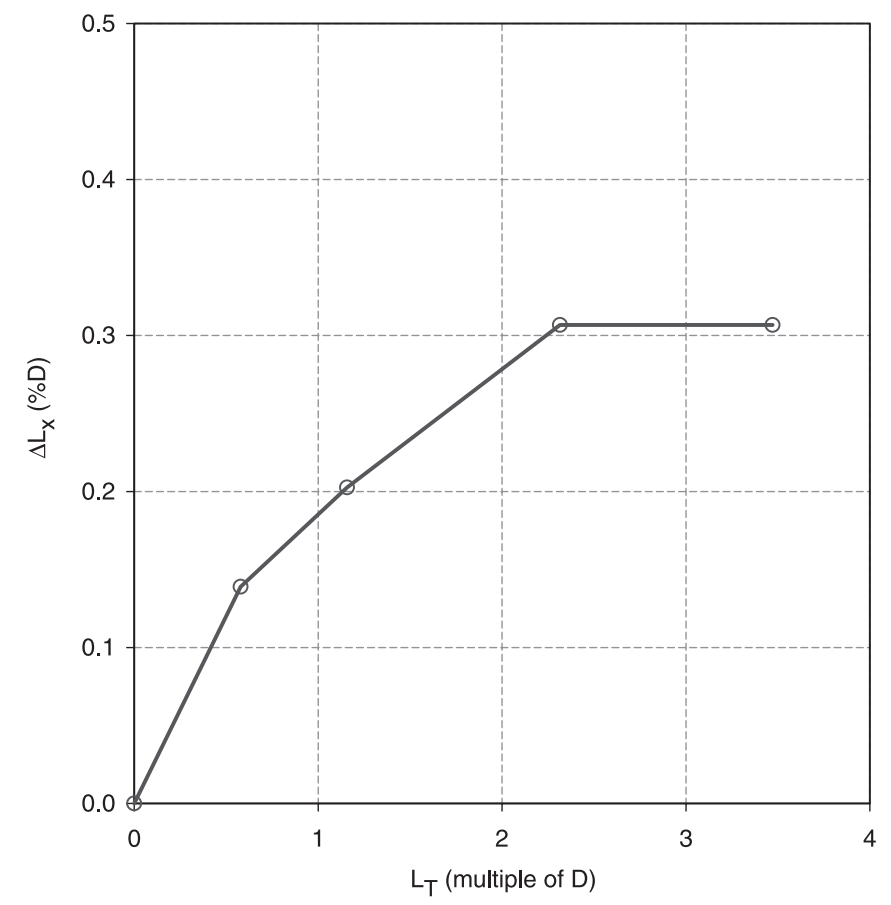

nel is completed, the settlement above the tunnel approaches a constant value of about $-0.36 \% D$.

The shifting of the settlement trough can also be clearly illustrated by plotting transverse surface settlements at various longitudinal distances in the $y$ direction for $L_{\mathrm{T}}=3.5 \mathrm{D}$ (see Fig. 8). It is clear that the settlement trough shifts gradually from the left to the right, and the maximum ground surface settlement offsets the centerline of the pillar. Figure 9 shows the variation of the net offsets $\left(\Delta L_{x}\right)$ of the maximum ground surface settlements with different $L_{\mathrm{T}}$ values at section E-E. The net offset is the offset $\left(L_{x}\right)$ at any $L_{\mathrm{T}}$ value minus the offset at $L_{\mathrm{T}}=0$. The offset at $L_{\mathrm{T}}=0$ is taken as the reference, since it is very small and negligible. It can be seen that the net offset increases gradually with an increase in $L_{\mathrm{T}}$, but it approaches a constant value (i.e., $32 \% D$ ) at $L_{\mathrm{T}}=2.5 \mathrm{D}$ or larger. The amount of offset is an indication of the amount of load transfer associated with the construction of the neighbouring parallel tunnel. The smaller the offset, the more uniform the load shared between the two tunnels. For instance, for $L_{\mathrm{T}}=0$ when the offset is the smallest and most negligible, the load is shared almost uniformly between the two tunnels. On the other hand, for $L_{\mathrm{T}}=2.5 \mathrm{D}$ or larger, more load is taken by the leading tunnel (i.e., the left tunnel here) than the lagging one (the right tunnel here), as illustrated later in the paper by different distributions of bending moments and axial forces in the tunnel linings for various $L_{\mathrm{T}}$ values.

Figure 10 shows the variations of the maximum ground surface settlement $\left(\delta_{z \max }\right)$ at section E-E with different $L_{\mathrm{T}}$ values. The maximum ground surface settlement measured in the Heathrow Express trial tunnel and the computed maximum settlement for a single NATM tunnel (Tang 2001) are also included for reference. It can be seen that $\delta_{z \max }$ remains almost constant for different $L_{\mathrm{T}}$ values, even though a small maximum ground settlement occurs at $L_{\mathrm{T}}=2.3 D(20 \mathrm{~m})$. This is probably because when $L_{\mathrm{T}}=2.3 \mathrm{D}$, the right drift of the left tunnel and the left drift of the right tunnel, both of which are closest to the pillar, are constructed simultaneously.

\section{Bending moments in the tunnel lining}

Figure 11 shows the distributions of the bending moment at section $\mathrm{E}-\mathrm{E}$ in the lining of both the left and right tunnels for $L_{\mathrm{T}}=30 \mathrm{~m}$ (i.e., $3.5 \mathrm{D}$ ). In addition, the bending moment from a single tunnel (Tang 2001) is shown for comparison. It should be noted that the actual properties of the shotcrete, such as stiffness, are time dependent and are not considered in the parametric analyses. Hence, the computed values of bending moments should only be taken for comparative purposes. It can be seen in Fig. 11 that the distributions of the bending moment are similar in both tunnels. The maximum and minimum bending moments occur at the left heel and the invert of the tunnels, respectively. The magnitude of the bending moments is greater in the left tunnel than in the right tunnel. This suggests that the left tunnel carries a larger portion of the load than the right tunnel, due to the large $L_{\mathrm{T}}=3.5 \mathrm{D}$. The strong resemblance between the bending moment distributions in the left tunnel and the single tunnel suggests that the left tunnel in the twin tunnel construction essentially behaves as a single tunnel, due to the large $L_{\mathrm{T}}$.

Figure 12 shows the variations of the bending moment in both the left and right tunnels at $y=-75 \mathrm{~m}$ (or $y=-8.6 D$ ) with different $L_{\mathrm{T}}$ values. It can be seen that the magnitude of the bending moment in the lining of the left tunnel increases with an increase in $L_{\mathrm{T}}$. The bending moments at the invert and close to the right springline regions (i.e., the pillar springline) are the most prominent. This is consistent with the results of Kim et al. (1998), who reported that the incremental bending moment of the existing tunnel is largest at the pillar springline regions. On the other hand, the influence of $L_{\mathrm{T}}$ on the bending moment distributions of the right tunnel is mainly at the invert region. The increments at the other locations around the right tunnel opening are relatively not very significant.

Figure 13 shows the variations of the maximum incremental bending moment in the lining with $L_{\mathrm{T}}$. As expected, the maximum incremental bending moment is the same for both left and right tunnels when $L_{\mathrm{T}}=0$, suggesting equal sharing of the load. As $L_{\mathrm{T}}$ increases, there is a transfer of load from the right tunnel to the left tunnel, leading to an increase in the bending moment in the left tunnel but a decrease in the bending moment in the right tunnel.

\section{Axial forces in the tunnel lining}

Figures $14 a$ and $14 b$ show the variations of axial force in the lining at section E-E with different $L_{\mathrm{T}}$ values for the left and right tunnels, respectively. It can be seen that the influence of $L_{\mathrm{T}}$ on the axial force is greatest at the pillar springline and at the invert. In the left tunnel, there is an increase in the axial force at the left springline with an increase in $L_{\mathrm{T}}$, illustrating a load transfer from the right tunnel to the left tunnel. Consistently, as $L_{\mathrm{T}}$ increases, the load 
Fig. 10. Variations of maximum normalized ground surface settlement with $L_{\mathrm{T}}$.

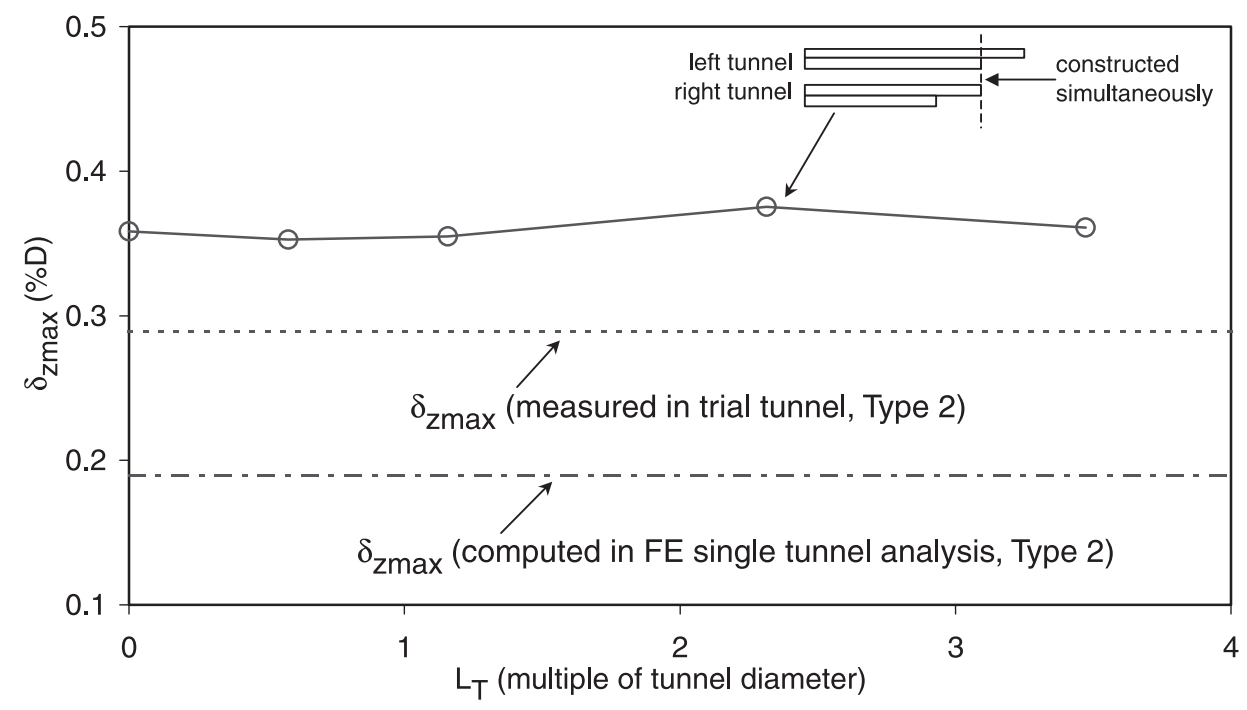

Fig. 11. Bending moment $(\mathrm{kN} \cdot \mathrm{m})$ in lining at section $\mathrm{E}-\mathrm{E}(y=$ $-8.6 D$, approaching plane strain conditions) for $L_{\mathrm{T}}=3.5 \mathrm{D}$.

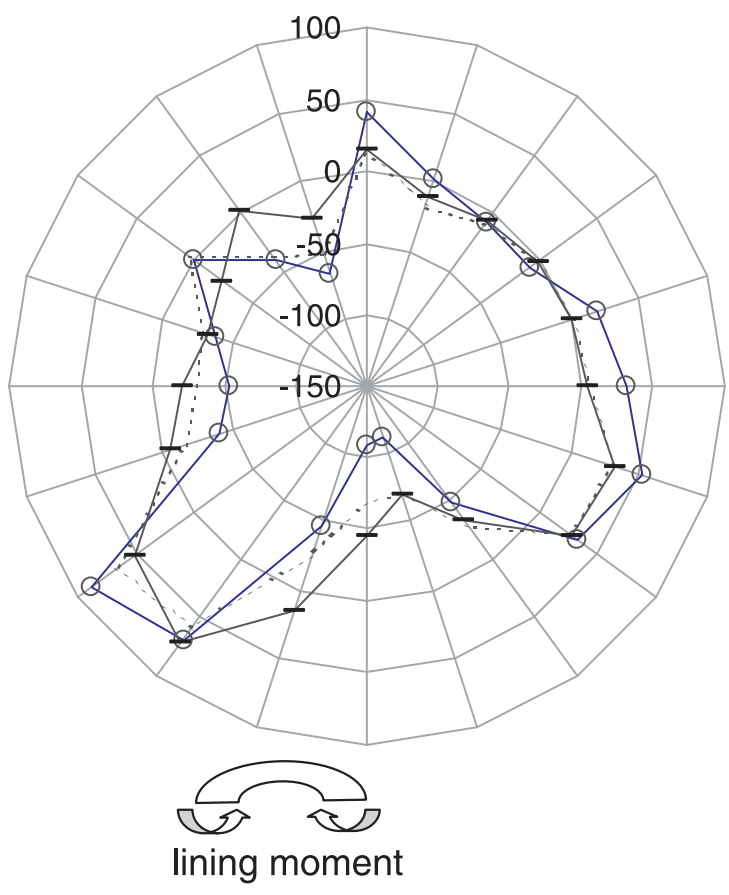

O- Left tunnel

— Right tunnel

-... - Single tunnel

transfer mechanism leads to a decrease in the axial force at the right springline of the right tunnel. The observed variations of the axial force with different $L_{\mathrm{T}}$ values are consistent with the bending moment distributions shown in Fig. 13.

\section{Excess pore-water pressures induced by tunnel construction}

Figures $15 a-15 e$ show the normalized excess pore-water distributions $\left(\Delta u_{\mathrm{exc}} / u_{\mathrm{o}}\right)$ around the tunnel openings at various longitudinal distances for $L_{\mathrm{T}}=30 \mathrm{~m}(3.5 D)$. For ease of comparison, the computed excess pore-water pressure $\left(\Delta u_{\text {exc }}\right)$ at each location is normalized by the initial hydrostatic pore-water pressure at its corresponding location $\left(u_{\mathrm{o}}\right)$. As a reminder, it is noted that the initial water table is located $5 \mathrm{~m}$ below the ground surface and the hydrostatic pore-water pressure at the centerline of the longitudinal tunnel axis is $147 \mathrm{kPa}$. At $y=0$, there is about a $50 \%$ reduction in the pore-water pressure $\left(\Delta u_{\mathrm{exc}} / u_{\mathrm{o}}=-0.5\right)$ at the left shoulder and the invert of the left tunnel, resulting mainly from the stress reduction due to the excavation of the left drift of the left tunnel. No significant change in the pore-water pressure is computed in the soil around the right tunnel, however. It should be noted that the change in the pore-water pressure due to shearing is relatively insignificant as a result of the small mobilized shear strains (Tang 2001).

After the excavation of the right drift of the left tunnel at $y=-20 \mathrm{~m}$ (see Fig. 15b), further significant reductions in the pore-water pressure, i.e., $\Delta u_{\mathrm{exc}} / u_{\mathrm{o}} \approx-1$, occur at the crown, right shoulder, invert, and right heel of the left tunnel. At this stage, again, no noticeable change in the pore-water pressure is computed in the soil around the right tunnel.

Due to the excavation of the left drift of the right tunnel at $y=-30 \mathrm{~m}$ (i.e., $-3.5 D$ ), there are, as expected, significant excessive negative pore-water pressures $\left(\Delta u_{\mathrm{exc}} / u_{\mathrm{o}} \approx-0.7\right)$ induced at the left drift of the right tunnel, mainly due to the stress reduction as a result of the excavation. On the other hand, the excessive negative pore-water pressures induced at the left drift of the left tunnel reduce from $\Delta u_{\mathrm{exc}} / u_{\mathrm{o}} \approx-1$ to -0.75 at both the shoulder and the heel and from $\Delta u_{\mathrm{exc}} / u_{\mathrm{o}} \approx-0.7$ to -0.5 at the left springline (comparing Figs. $15 b$ and $15 c$ ). This implies that there is a load transfer from the right to the left tunnel to cause a reduction in excessive negative pore-water pressures, i.e., the pore-water 
Fig. 12. Variation of bending moment $(\mathrm{kN} \cdot \mathrm{m})$ in lining at section $\mathrm{E}-\mathrm{E}(y=-8.6 D$, approaching plane strain conditions) with different $L_{\mathrm{T}}$ values: $(a)$ left tunnel; $(b)$ right tunnel.

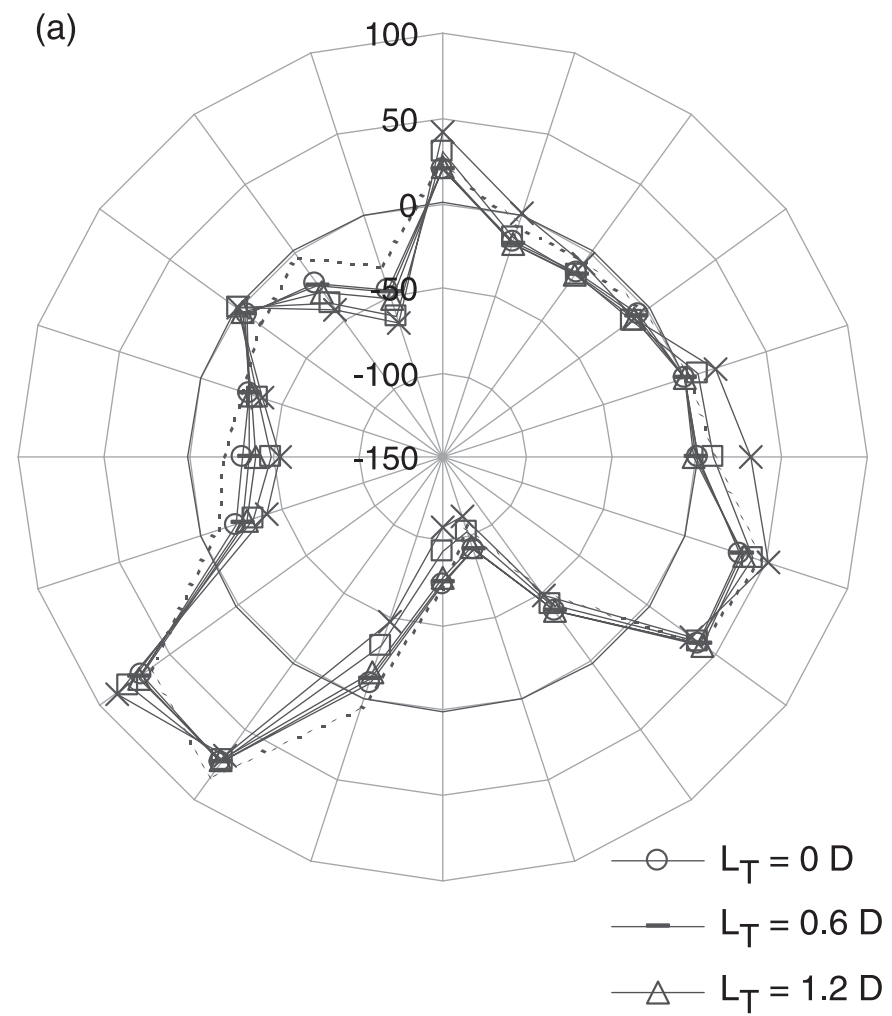

Fig. 13. Variation of maximum incremental bending moment $\left(M_{\max }=\right.$ computed bending moment from parallel tunnel analysis - computed bending moment from single tunnel analysis) in lining at section E-E $(y=-8.6 D$, approaching plane strain conditions) with different $L_{\mathrm{T}}$ values.

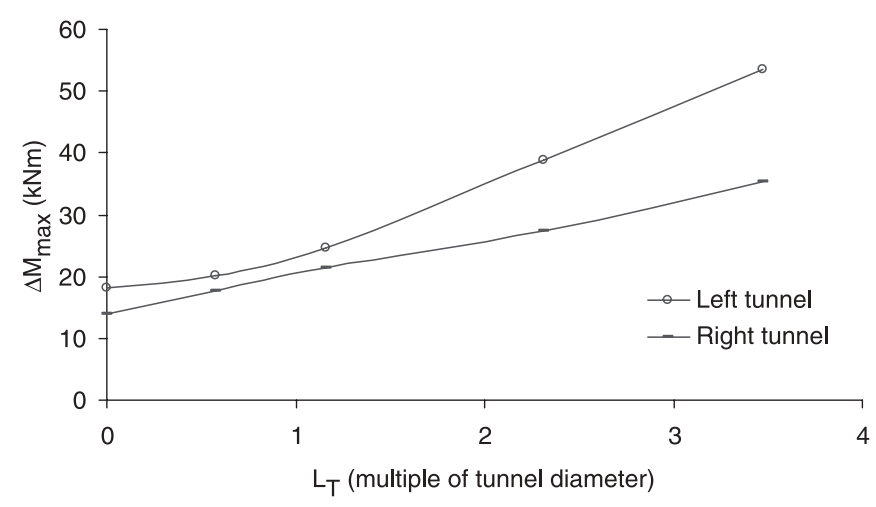

pressure increases, in the soil around the left drift of the left tunnel, as illustrated.

At section E-E (i.e., $y=-75 \mathrm{~m}$ or $8.6 D$ ), the distribution of the excess negative pore-water pressures ranges from $\Delta u_{\mathrm{exc}} / u_{\mathrm{o}} \approx-0.25$ at the left springline to -0.5 at the right shoulder and at the right springline of the left tunnel. On the other hand, the induced excessive negative pore-water pressures at the right tunnel lie between $\Delta u_{\mathrm{exc}} / u_{\mathrm{o}} \approx-0.5$ and -0.8 , which are larger in magnitude than those at the left tunnel (i.e., larger stress reduction). The smaller excessive negative pore-water pressure induced in the left tunnel is due

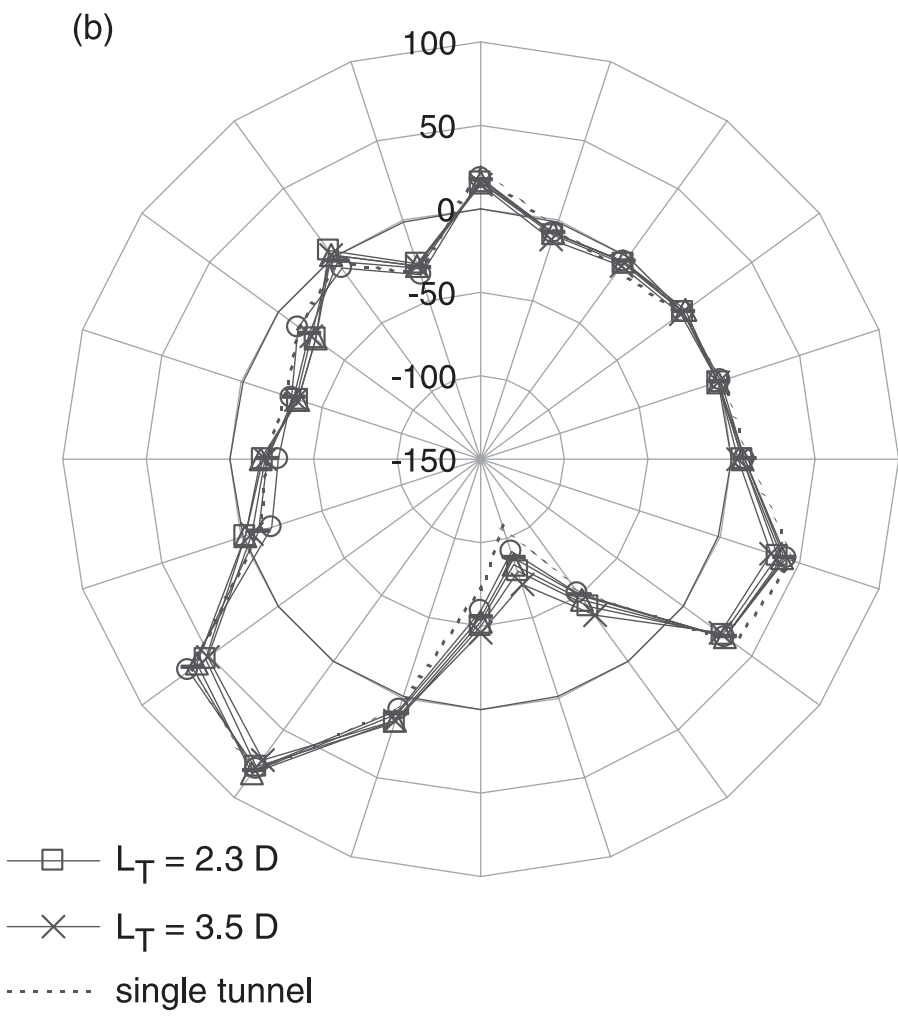

to an increase in the load via the load transfer mechanism as illustrated in Figs. $15 a-15 c$.

Figure 16 shows the variations of normalized excess porewater pressure $\left(\Delta u_{\mathrm{exc}} / u_{\mathrm{o}}\right)$ at representative locations around the tunnel opening with time for $L_{\mathrm{T}}=30 \mathrm{~m}(3.5 D)$. It can be seen that the approach of the left drift of the left tunnel leads to a small increase in the pore-water pressure (up to $\left.\Delta u_{\mathrm{exc}} / u_{\mathrm{o}} \approx 0.25\right)$ around the left tunnel. At 20 days into construction, there is a significant reduction in the pore-water pressure around the left drift of the left tunnel (see Figs. 16a-16d). Subsequently, the reduced pore-water pressures at the left tunnel recover rather rapidly. At 30 days into construction, the pore-water pressures at the crown, invert, right shoulder, and right springline of the left tunnel appear to have reached stable conditions. Generally, the analyses results show that the pore pressure ratio, $\Delta u / u_{0}$, approximately ranges from 0.3 to 0.5 at these locations.

The pore-water pressure responses around the right tunnel at sections $\mathrm{C}-\mathrm{C}$ and $\mathrm{D}-\mathrm{D}$ due to the construction of the right tunnel are similar to those of the left tunnel at sections $\mathrm{A}-\mathrm{A}$ and $\mathrm{B}-\mathrm{B}$, respectively, except that there is a time lag of 12 days. The amount of recovery in the pore-water pressures is larger in the left tunnel than in the right tunnel, however, due to the load transfer from the right tunnel to the left tunnel during the advancement of the twin tunnels.

Figure 17 shows the pore-water pressure distributions around the twin tunnels at section E-E. The computed porewater pressure distributions correspond to the construction at the 30th day after the tunnel face of the left drift of the left tunnel passing the reference section for various $L_{\mathrm{T}}$ values. The measured pore-water pressures for the trial tunnel, 
Fig. 14. Variation of axial force $(\mathrm{kN} / \mathrm{m})$ at section $\mathrm{E}-\mathrm{E}(y=-8.6 D$, approaching plane strain conditions $)$ with different $L_{\mathrm{T}}$ values: (a) left tunnel; (b) right tunnel.

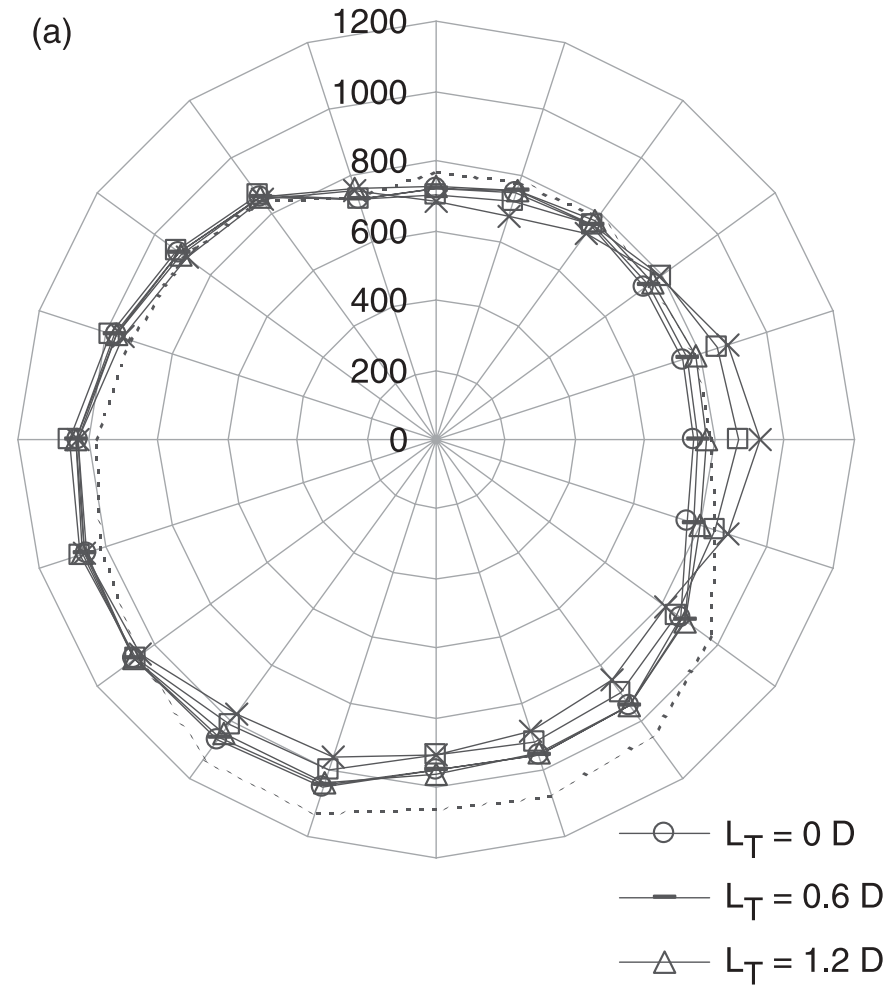

which were measured at the end of the construction of type 2 tunnel section, corresponding to the 24th day in the tunnel construction are also shown in Fig. 17 for comparison (Deane and Bassett 1995). The distributions are highly nonsymmetrical in both tunnels. Due to the twin tunnel interactions, the magnitude of the induced excess negative pore-water pressures is the largest at the right heel of the left tunnel and at the left heel of the right tunnel. The influence of $L_{\mathrm{T}}$ on the excess pore-water pressure is much more significant in the right tunnel than in the left tunnel. In the right tunnel, the longer the $L_{\mathrm{T}}$, the larger the induced negative pore-water pressure.

\section{Conclusions}

It is generally recognised that the interactions between tunnels is complex, especially when using the new Austrian tunnelling method (NATM). The interaction between two large and closely spaced parallel tunnels was investigated in three dimensions by finite element analysis. Special attention was paid to the influence of the lagging distance $\left(L_{\mathrm{T}}\right)$ between the leading (left) and lagging (right) tunnels and to the load transfer mechanism between the two tunnels. Based on the systematic 3D coupled finite element analyses, the following conclusions are drawn:

(1) Due to twin tunnel interactions, there is a reduction in the deformation at the pillar springline of the tunnel as compared with those due to the construction of a single tunnel in a greenfield site. The lagging distance between the two excavated faces of the twin tunnels has a stronger influence on the horizontal movement than on the vertical movement of each tunnel and significantly af-

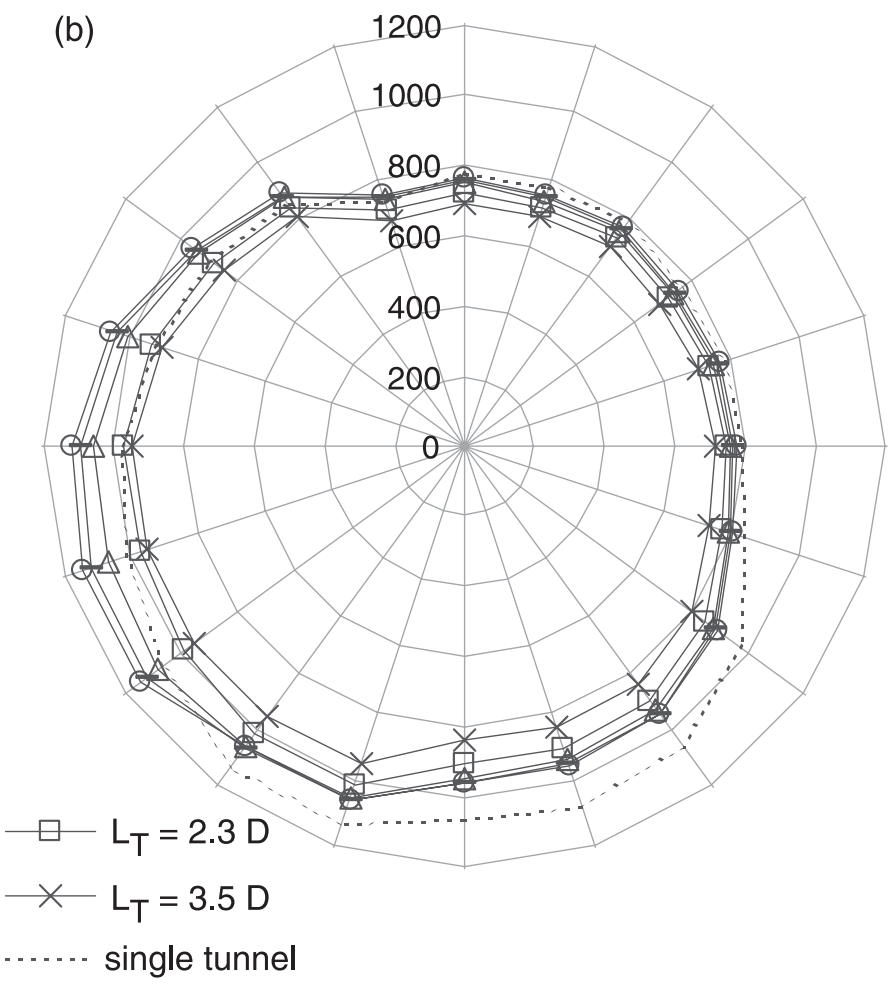

fects the shortening of the horizontal diameter of the tunnels. The change in pillar width $(\Delta H)$ between the two tunnels appears to be an approximately linear function of $L_{\mathrm{T}}$. The reduction in the vertical tunnel diameter appears to be independent of $L_{\mathrm{T}}$, however.

(2) There is a shift in the settlement trough above the leading (left) tunnel to the lagging (right) tunnel at various longitudinal distances for non-zero $L_{\mathrm{T}}$ cases. The location of the maximum settlement due to the construction of the twin tunnels offsets the centerline of the pillar. The offset gradually increases with an increase in $L_{\mathrm{T}}$ but approaches a constant value (i.e., $32 \% D$ ) at $L_{\mathrm{T}}=2.5 \mathrm{D}$ or larger. The magnitude of the offset indicates the amount of load transfer associated with the construction of a neighbouring parallel tunnel. The smaller the offset, the more uniform the load shared between the two tunnels. The magnitude of the maximum settlements appears to be almost independent of $L_{\mathrm{T}}$, however.

(3) The distributions of the bending moments induced in the lining are similar in shape, but they are different in magnitude in the two tunnels. The magnitude of the bending moments is largest in the left tunnel and smallest in the right tunnel. This suggests that the left tunnel carries a larger portion of the load than the right tunnel for nonzero $L_{\mathrm{T}}$ values. As $L_{\mathrm{T}}$ increases, there is a transfer of load from the right tunnel to the left tunnel, leading to an increase in the bending moment in the left tunnel but a decrease in the bending moment in the right tunnel. The influence of $L_{\mathrm{T}}$ on the axial force is greatest at the pillar springline and the invert. Due to the load transfer from the right tunnel to the left tunnel, there is an increase in the axial force at the left springline of the left 
Fig. 15. Normalized excess pore-water pressures at various transverse sections around the tunnel openings: $(a)$ at $y=0 D$ (at tunnel face); $(b)$ at $y=-2.3 D(-20 \mathrm{~m}$ behind tunnel face); $(c)$ at $y=-3.5 D(-30 \mathrm{~m}$ behind tunnel face); $(d)$ at $y=-5.8 D(-50 \mathrm{~m}$ behind tunnel face); $(e)$ at $y=-8.6 D(-75 \mathrm{~m}$, approaching plane strain conditions). Abbreviations as in Fig. 4.
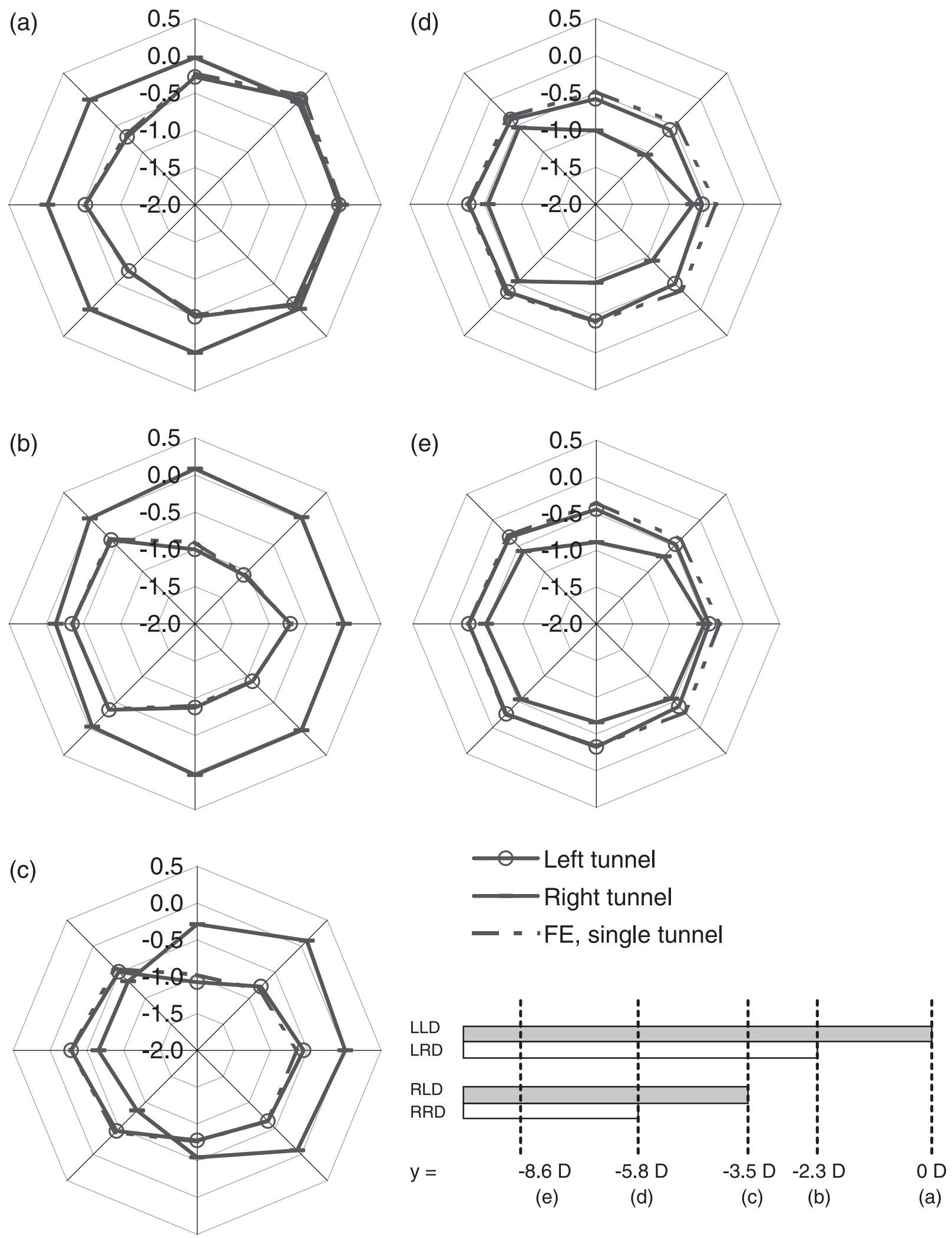
Fig. 16. Variations of normalized excess pore-water pressures $\left(\Delta u / u_{\mathrm{o}}\right)$ with time at various locations around the tunnel openings: $(a)$ at the crown; $(b)$ at the invert; $(c)$ at the left springline; $(d)$ at the left shoulder; $(e)$ at the left springline; $(f)$ at the right shoulder. A-A, tunnel face of LLD at the reference section (0th day); B-B, tunnel face of LRD at the reference section (8th day after LLD tunnel face passes reference section); $\mathrm{C}-\mathrm{C}$, tunnel face of RLD at the reference section (12th day after LLD tunnel face passes reference section); D-D, tunnel face of RRD at the reference section (20th day after LLD tunnel face passes reference section).
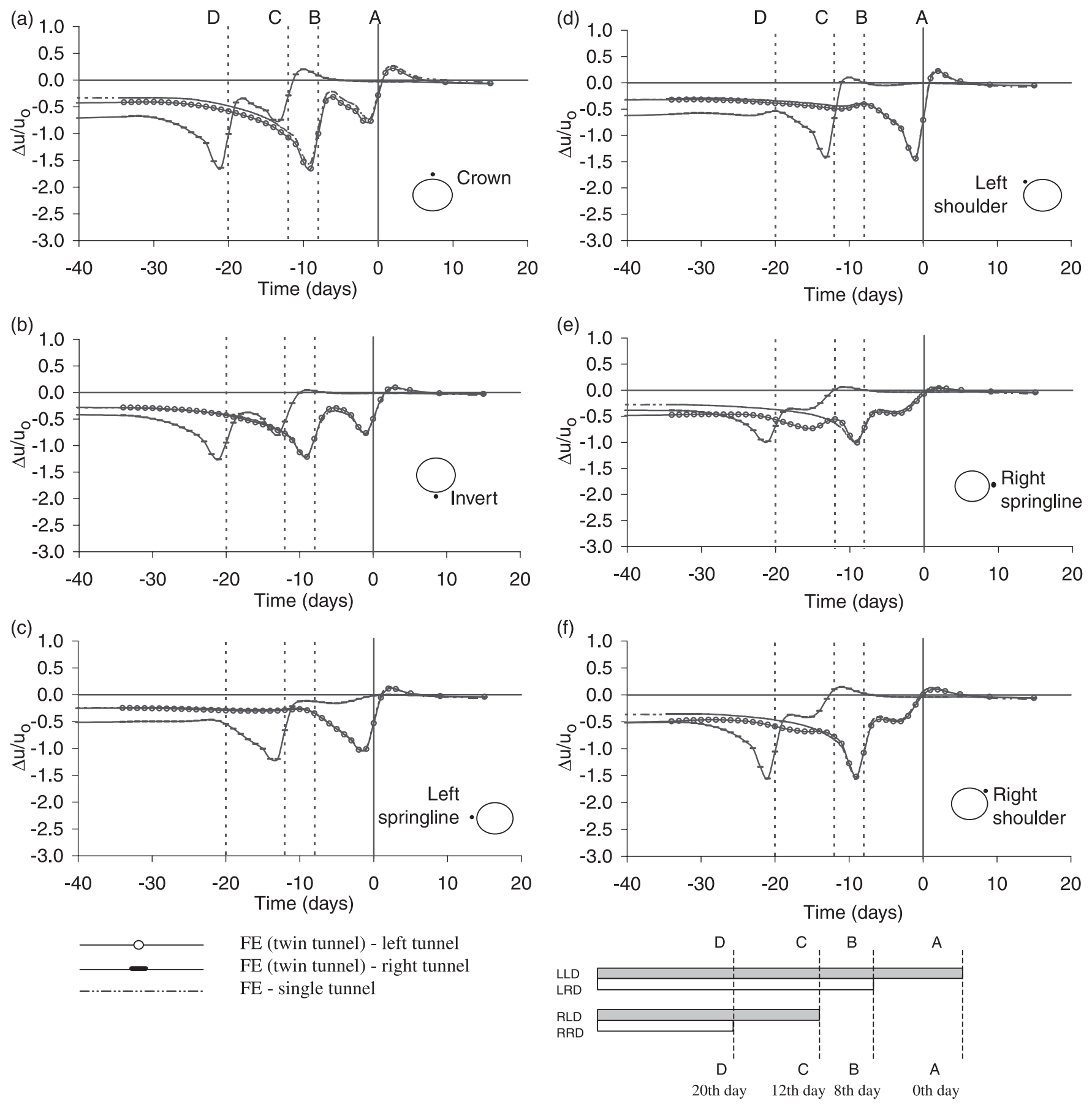

tunnel and a decrease in the axial force at the right springline of the right tunnel as $L_{\mathrm{T}}$ increases. The load transfer mechanism is also revealed by considering the changes in the pore-water pressure around the twin tunnels. Due to the twin tunnel interaction, the magnitude of the induced excess negative pore-water pressures is

largest at the right heel of the left tunnel and at the left heel of the right tunnel. The distributions of the porewater pressure are highly nonsymmetrical in both tunnels. The influence of $L_{\mathrm{T}}$ on the excess pore-water pressure is much more significant in the right tunnel than in the left tunnel. In the right tunnel, the longer the 
Fig. 17. Variations of excess pore-water pressures $(\Delta u$ in $\mathrm{kPa})$ with different $L_{\mathrm{T}}$ values: $(a)$ left tunnel; $(b)$ right tunnel.

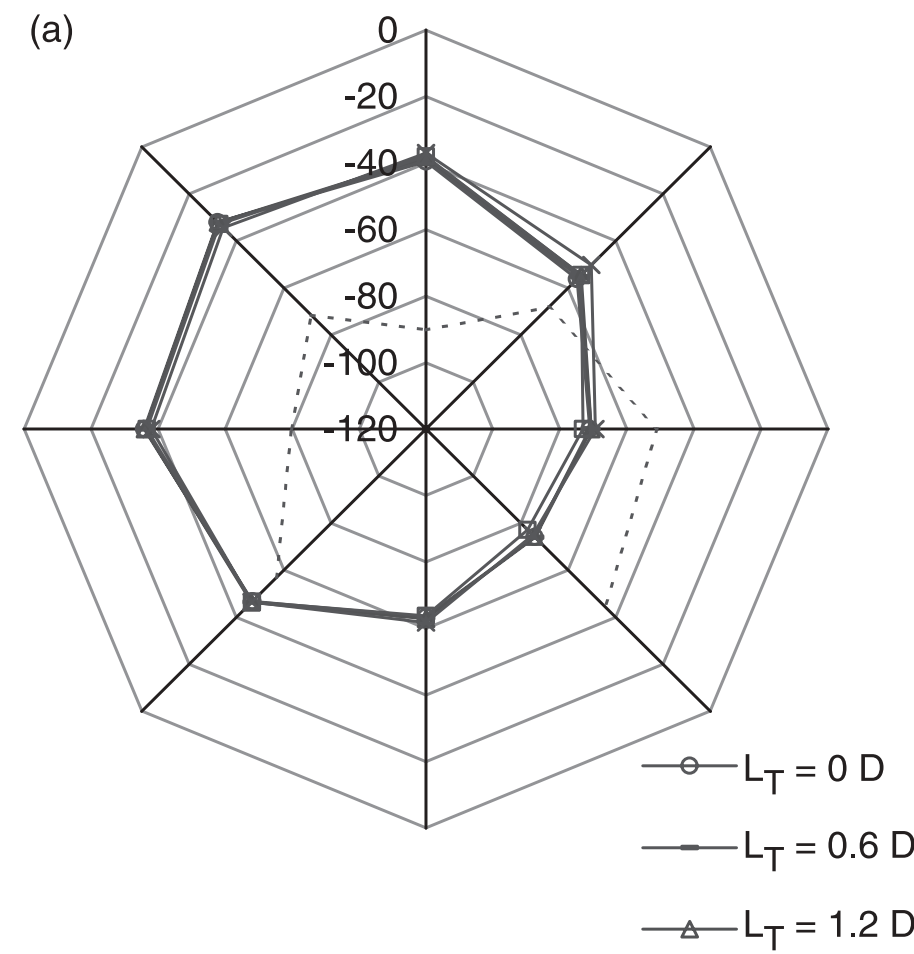

$L_{\mathrm{T}}$, the larger the induced negative pore-water pressures. There is a rapid recovery of pore-water pressures after each stage of excavation.

\section{Acknowledgements}

This research project is supported by research grants HKUST714/96E and DAG96/97.EG37 provided by the Research Grants Council of the Hong Kong Special Administration Region and research grant HIA96/97.EG03 provided by the Hong Kong University of Science and Technology.

\section{References}

Abaqus, Inc. 1998. ABAQUS user's manual, version 5.8. Abaqus, Inc. (formerly Hibbitt, Karlsson and Sorensen Inc.), Pawtucket, R.I.

Adachi, T., Kimura, M., and Osada, H. 1993. Interaction between multi-tunnels under construction. In Proceedings of the 11th Southeast Asian Geotechnical Conference, Singapore, May 1993. National University of Singapore and Nanyang Technological University, Singapore. pp. 51-60.

Addenbrooke, T.I., and Potts, D.M. 1996. Twin tunnel construction - ground movements and lining behaviour. In Proceedings of the 1st International Symposium on the Geotechnical Aspects of Underground Construction in Soft Ground, London, 1517 Apr. 1996. A.A. Balkema, Rotterdam, The Netherlands. pp. 441-446.

Addenbrooke, T.I., and Potts, D.M. 2001. Finite element analysis of St. James Park greenfield reference site. In Building response to tunnelling. Edited by J.B. Burland, J.R. Standing, and F.M. Jardine. Thomas Telford, London, U.K. Vol. 1, pp. 177-194.

Addenbrooke, T.I., Potts, D.M., and Puzrin, A.M. 1997. The influence of pre-failure soil stiffness on the numerical analysis of twin tunnel construction. Géotechnique, 47(3): 693-712.

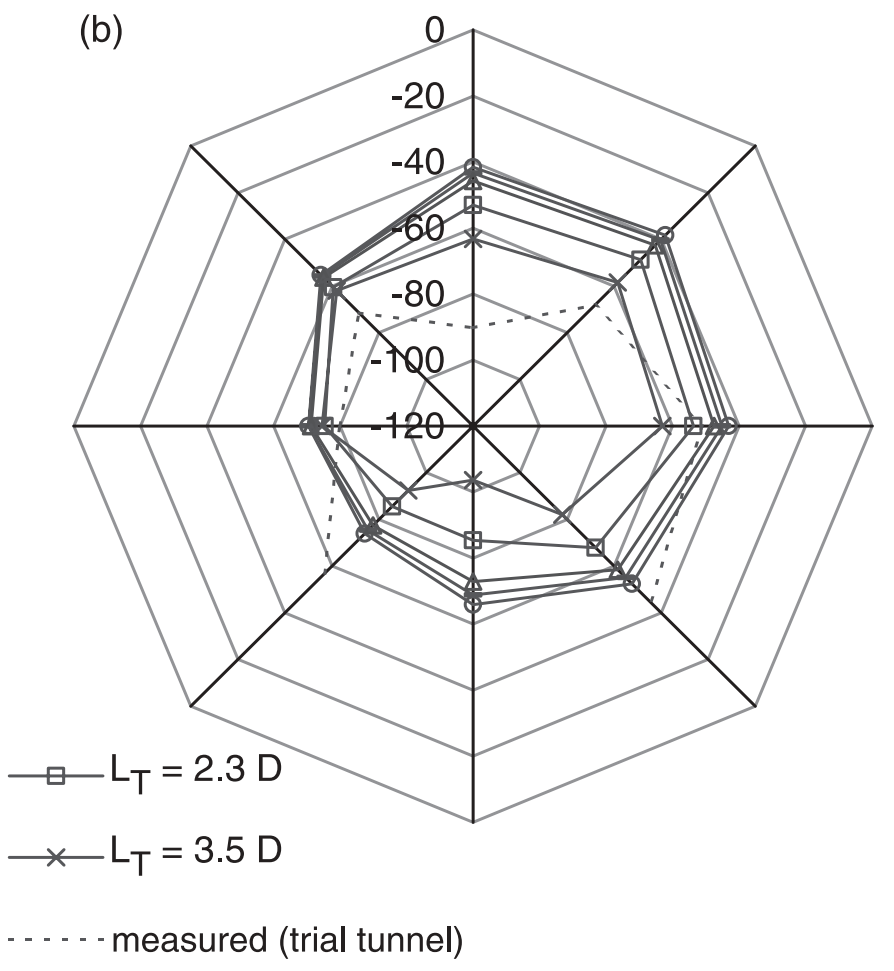

Burland, J.B., and Kalra, J.C. 1986. Queen Elizabeth II Conference Centre: geotechnical aspects. Proceedings of the Institution of Civil Engineers, Part 1, 80: 1479-1503.

Chapman, D.N., Rogers, C.D.F., and Hunt, D.V.L. 2002. Prediction of settlement above closely spaced multiple tunnel constructions in soft ground. In Proceedings of the 3rd International Symposium on the Geotechnical Aspects of Underground Construction in Soft Ground, Toulouse, 23-25 Oct. 2002. A.A. Balkema, Rotterdam, The Netherlands. pp. 299-304.

Dasari, G.R., Rawlings, C.G., and Bolton, M.D. 1996. Numerical modelling of a NATM tunnel construction in London Clay. In Proceedings of the 1st International Symposium on the Geotechnical Aspects of Underground Construction in Soft Ground, London, 15-17 Apr. 1996. A.A. Balkema, Rotterdam, The Netherlands. pp. 91-496.

Deane, A.P., and Bassett, R.H. 1995. The Heathrow Express trial tunnel - geotechnical Engineering. Proceedings of the Institution of Civil Engineers, 113: 144-156.

Fang, Y.S., Lin, J.S., and Su, C.S. 1994. An estimation of ground settlement due to shield tunnelling by the Peck-Fujita method. Canadian Geotechnical Journal, 31: 431-443.

Fujita, K. 1985. On the surface settlements caused by various methods of shield tunnelling. In Proceeding of the 11th International Conference on Soil Mechanics and Foundation Engineering, San Francisco, 12-16 Aug. 1985. A.A. Balkema, Rotterdam, The Netherlands. Vol. 4, pp. 609-610.

Ghaboussi, J., and Ranken, R.E. 1977. Interaction between two parallel tunnels. International Journal for Numerical and Analytical Methods in Geomechanics, 1: 75-103.

Hoyaux, B., and Ladanyi, B. 1970. Gravitational stress field around a tunnel in soft ground. Canadian Geotechnical Journal, 7: 54-61.

Kim, S.H., Burd, H.J., and Milligan, G.W.E. 1998. Model testing of closely spaced tunnels in clay. Géotechnique, 48(3): 375-388.

Mair, R.J., and Taylor, R.N. 1997. Theme lecture: Bored tunnelling in the urban environment. In Proceedings of the 14th Interna- 
tional Conference on Soil Mechanics and Foundation Engineering, Hamburg, 6-12 Sept. 1997. Vol. 4. A.A. Balkema, Rotterdam. pp. 2353-2385.

McWilliam, F. 1991. Jet setting under Bonn. Tunnels \& Tunnelling International, April, pp. 29-31.

Murphy, P. 1993. Design and construction of the A20 Round Hill Tunnels. Tunnels \& Tunnelling International, April, pp. 23-25.

New, B.M., and Bowers, K.H. 1994. Ground movement model validation at Heathrow. In Tunnelling '94, Proceedings of the Institute of Mining and Metallurgy Conference, London. Chapman and Hall, London, U.K. pp. 302-329.

Oettl, G., Stark, R.F., and Hofstetter, G. 1998. A comparison of elastic-plastic soil models for 2D FE analyses of tunnelling. Computers and Geotechnics, 23: 19-38.

Peck, R.B. 1969. Deep excavations and tunnelling in soft ground: state-of-the-art report. In Proceedings of the 7th International Conference on Soil Mechanics and Foundation Engineering, Mexico City, 25-29 Aug. 1969. A.A. Balkema, Rotterdam, The Netherlands. pp. 225-290.

Sauer, G., and Gold, H. 1989. NATM ground support concepts and their effects on contracting practices. In Proceedings of the 9th Rapid Excavation and Tunneling Conference (RETC), Los Angeles, 11-14 June 1989. pp. 67-86.
Tang, D.K.W. 2001. Numerical studies of multiple NATM tunnel interaction in soft ground. M.Phil. thesis, Department of Civil Engineering, Hong Kong University of Science and Technology, Hong Kong.

Tang, D.K.W., Lee, K.M., and Ng, C.W.W. 1999. Stress paths around a 3D numerically simulated NATM tunnel in stiff clay. In Proceedings of the 2nd International Symposium on Geotechnical Aspects of Underground Construction in Soft Ground, Tokyo. Edited by O. Kusakabe, K. Fujita, and Y. Miyazaki. A.A. Balkema, Rotterdam, The Netherlands. Vol. 1. pp. 443-449.

Terzaghi, H. 1942. Liner-plate tunnels on the Chicago subway. Proceedings of the American Society of Civil Engineers, 68(6): 862-899.

Ward, W.H., and Thomas, H.S.H. 1965. The development of earth loading and deformation in tunnel linings in London Clay. In Proceedings of the 6th International Conference on Soil Mechanics and Foundation Engineering, Toronto, Ont. A.A. Balkema, Rotterdam, The Netherlands. Vol. 2, pp. 432-436.

Withers, A.D., Page, D.P., and Linney, L.F. 2001. Geology and geotechnical properties. In Building response to tunnelling. Edited by J.B. Burland, J.R. Standing, and F.M. Jardine. Thomas Telford, London, U.K. Vol. 1, pp. 57-81. 